\title{
Ferric Iron Nanoparticle Formation Mediated By Negatively Charged Polypeptides
}

\author{
Vamsi Krishna Aluru \\ West Virginia University
}

Follow this and additional works at: https://researchrepository.wvu.edu/etd

\section{Recommended Citation}

Aluru, Vamsi Krishna, "Ferric Iron Nanoparticle Formation Mediated By Negatively Charged Polypeptides" (2010). Graduate Theses, Dissertations, and Problem Reports. 2167.

https://researchrepository.wvu.edu/etd/2167

This Thesis is protected by copyright and/or related rights. It has been brought to you by the The Research Repository @ WVU with permission from the rights-holder(s). You are free to use this Thesis in any way that is permitted by the copyright and related rights legislation that applies to your use. For other uses you must obtain permission from the rights-holder(s) directly, unless additional rights are indicated by a Creative Commons license in the record and/ or on the work itself. This Thesis has been accepted for inclusion in WVU Graduate Theses, Dissertations, and Problem Reports collection by an authorized administrator of The Research Repository @ WVU. For more information, please contact researchrepository@mail.wvu.edu. 


\title{
Ferric Iron Nanoparticle Formation Mediated By Negatively Charged Polypeptides
}

\author{
Vamsi Krishna Aluru \\ Thesis submitted to the \\ College of Engineering and Mineral Resources \\ at West Virginia University \\ in partial fulfillment of the requirements \\ for the degree of \\ Master of Science \\ in \\ Chemical Engineering
}

\begin{abstract}
Dr Robin S. Hissam, Chair
Dr David J. Klinke

Dr Charter D. Stinespring
\end{abstract}

Department of Chemical Engineering

\author{
Morgantown, West Virginia \\ 2010
}

Keywords: Biomineralization, Magnetotactic bacteria, Magnetosome, Nanoparticles Copyright 2010 Vamsi Krishna Aluru 


\title{
Abstract \\ Ferric Iron Nanoparticle Formation Mediated By Negatively Charged Polypeptides
}

\author{
Vamsi Krishna Aluru
}

The creation of magnetite particles by magnetotactic bacteria has been of great interest for a number of years. Previous studies have shown that magnetite nanocrystals have been synthesized in the presence of recombinant Mms6 protein. Mms6 plays a vital role in the biomineralization of bacterial magnetite nanocrystals. The objective of this research is to determine the effect of functional group type on size and shape of magnetic nanoparticles formed by biomineralization. Control over the size of nanoparticles is paramount. Use of nanoparticles as contrast agents in MRI is advantageous, as they are small enough to be localized in desired region by applying local magnetic fields. Sequences VA-Mms6, VA1, VA2, and VA3 were designed with modifications in the functional groups Mms6 sequence. Solutions of peptide were mixed with ferric and ferro salts and allowed to interact under inert atmosphere. The nanoparticles formed are examined under SEM and TEM and compared for differences. The SEM and TEM images of nanoparticles produced with the aid of the above peptides had similarity to those produced in the magnetotactic bacteria. However, discrete particles with a narrower size range were produced using the peptide VA2. XPS, AFM, DLS and MFM were also done on the synthesized nanoparticles. The results were in good agreement when compared to those with a standard control sample of magnetite nanoparticles. Use of peptides with different functional groups may provide a unique route to produce uniform magnetite nanocrystals with definite control of morphology. 


\section{Acknowledgement}

It is a pleasure to thank those who made this thesis possible. Firstly, I am heartily thankful to my advisor, Dr. Robin Hissam, without whom this project wouldn't have started. Her encouragement, guidance, and support from the initial to final level enabled me to understanding of the subject. I would also like to thank my committee members Dr. David Klinke and Dr. Charter Stinespring for all the support and advice they gave me throughout my project. I would like to acknowledge my lab mates Avram Siegel, Jaclyn Kokx, Andrew Graves, Logan May and Dr.Yogesh Kulkarni for helping me at different stages of my research. I would like to thank Srikanth Raghavan who helped me in characterization of magnetic particles. I would like to extend my appreciation to Dr. Chaoying and Julie Albert (University of Delaware) for TEM images. I would like to thank all my friends who were always with me in tough times. A special thanks to my best friends Vineeth Rao, Rohit Nara, Girish Nara, Vasu Nadapana, Sujith, Vyshnavi, Aditi Mehan, Kiran chaudhari, Kedar Panday, Manasa, Swathi and Soumya. I would like to thank all my cousins Madhava Rao, Krishnaveni, Srivalli, Srinivas and my sister Narmada for loving me always. Last but not the least, I would like to thank my parents Siva Rama Prasad and Maha Lakshmi for all the support they have given me all throughout my career. 


\section{Contents}

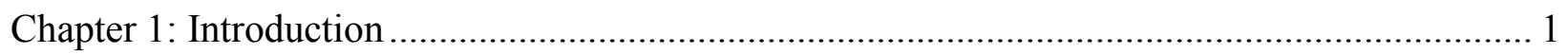

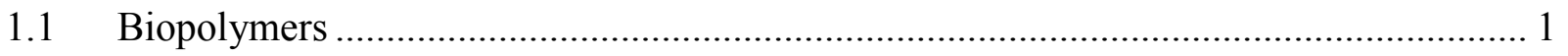

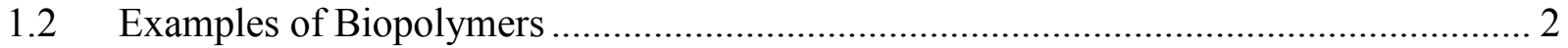

1.3 Synthesis of Iron Nanoparticles via chemical routes ..................................................... 3

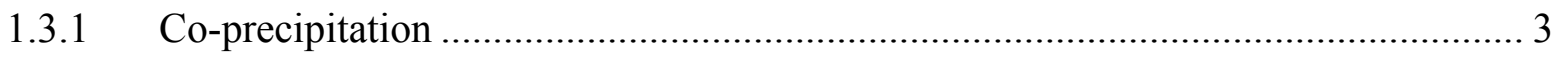

1.3.2 Thermal Decomposition ........................................................................................... 4

1.3.3 Two phase method (Microemulsion) ........................................................................... 4

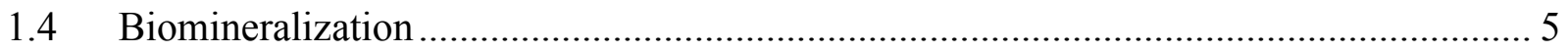

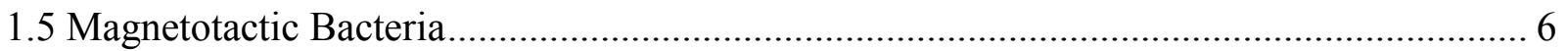

1.5.1 Bacterial Magnetite Particles.............................................................................. 7

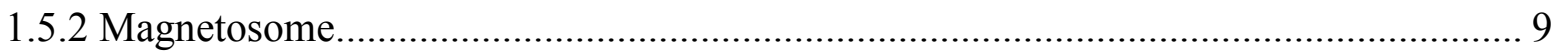

1.5.3 Bacterial Biomineralization Protein-Mms6 .......................................................... 10

1.6 Applications of Magnetic Nanoparticles.................................................................... 11

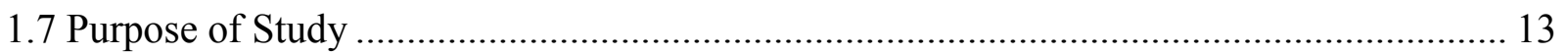

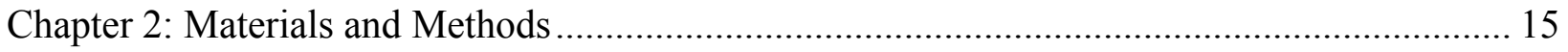

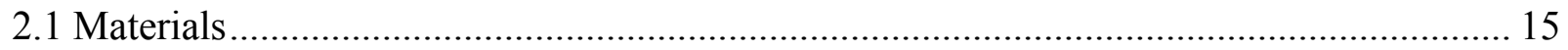

2.2 Design of New Plasmids and Ongoing Research Work.................................................... 16

2.3 New Expression Construction ..................................................................................... 17

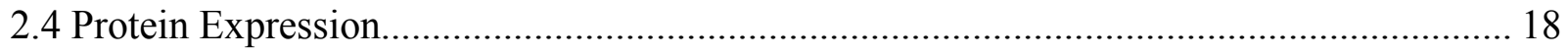

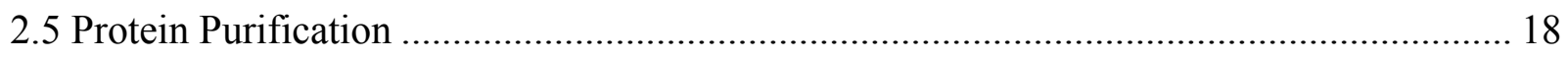

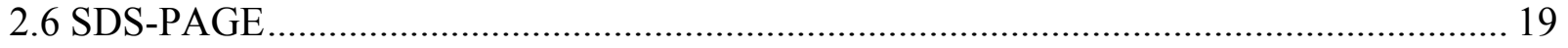




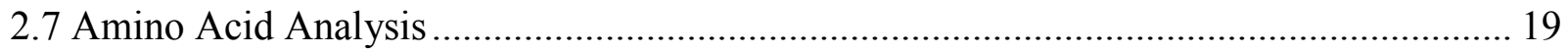

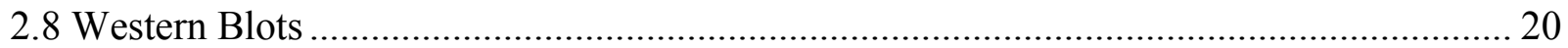

2.9 Synthesis of Magnetite nanoparticles using recombinant proteins .................................... 20

2.10 Characterization of Magnetite Nanoparticles................................................................... 21

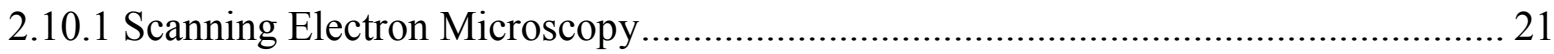

2.10.2 Transmission Electron Microscopy (TEM) ……………………………............... 21

2.10.3 X-ray Photoelectron Spectroscopy (XPS) ……………............................................. 22

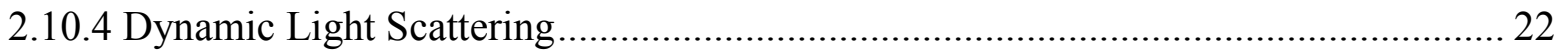

2.10.5 Atomic Force Microscopy (AFM) ………………............................................ 22

2.10.6 Magnetic Force Microscopy (MFM) ...................................................................... 23

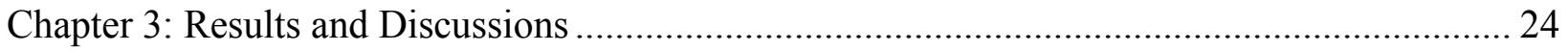

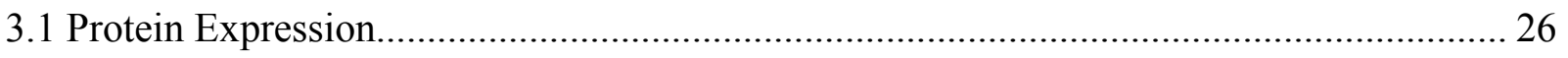

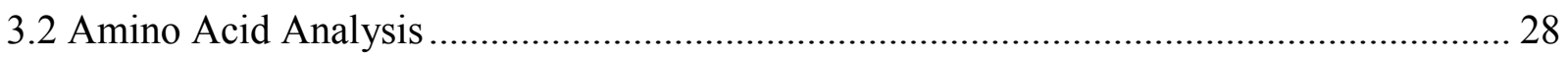

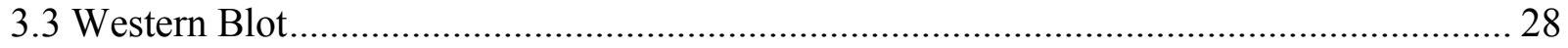

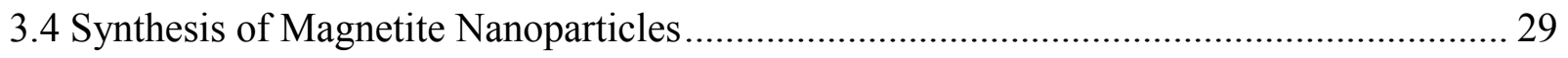

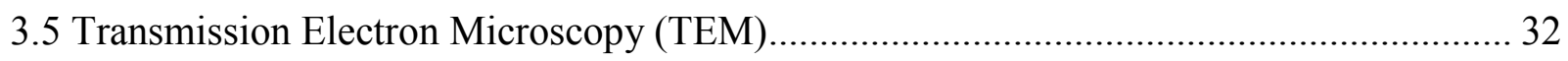

3.6 X-Ray Photoelectron Spectroscopy ………………….................................................... 34

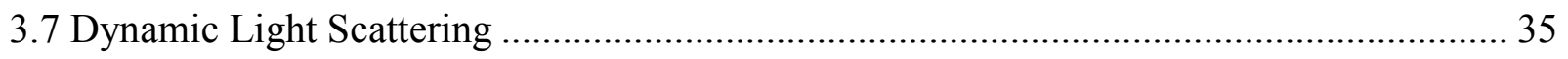

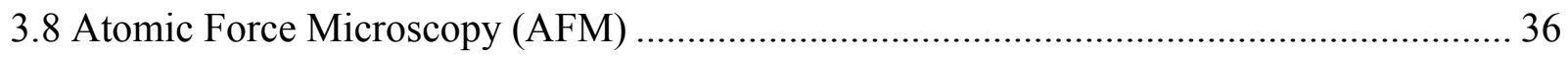

3.9 Magnetic Force Microscopy (MFM) ............................................................................ 38

Chapter4: Conclusions and Future Directions ............................................................................ 40

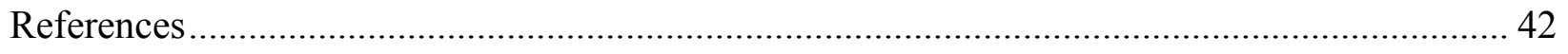

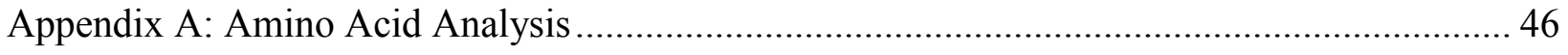

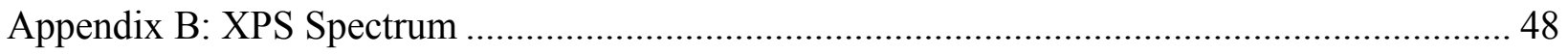




\section{List of Tables}

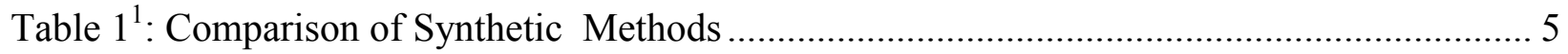

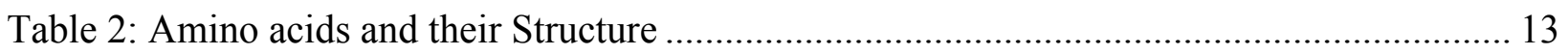

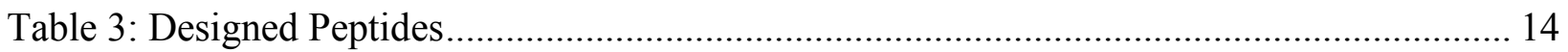

Table4:Optical density values of pJexpress414-VAMms6, pJexpress414-VA1, and

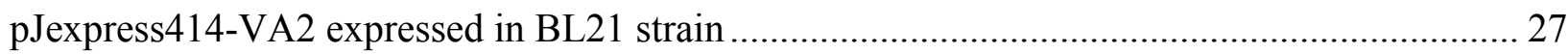

\section{List of Figures}

Figure 1: Schematic diagram of protein synthesis....

Figure 2: Schematic diagram of iron uptake mechanism in Magnetospirillum Magneticum strain

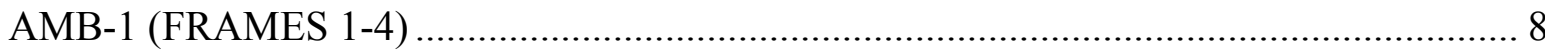

Figure 3 : A) iron crystals in presence of Mms6 $\quad$ B) iron crystals in absence of Mms6 …......... 10

Figure 4: Amino acid sequence of Mms6 deduced from the DNA sequence............................... 11

Figure 5: Functionalized magnetic nanoparticles accumulate in the tumor tissues via the drug delivery system (DDS). Magnetic nanoparticles can be used as a tool for cancer diagnosis by magnetic resonance imaging (MRI). Hyperthermia can be induced using alternating

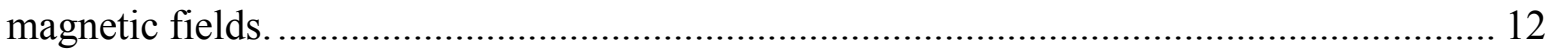

Figure 6 : Cloning strategy used for synthesis of amino acid................................................... 15

Figure 7: DNA sequence of new designed inserts with BamH1 and HindIII ends (* denotes stop codon)

Figure 8: Lane 1) 100bp Ladder, Lane 2) VA1, Lane 3) VA2, Lane 4)VA3, 1.5\% gel, 40 min @ $100 \mathrm{~V}$, stained with SYBR gold.

Figure 9 (a): Lane 1) 1 kb ladder, Lane 2) digested pET24a, (b) Lane 3) 100bp ladder, Lane 4) VA1, Lane 6) VA2, Lane 7) VA3, 1.5\% gel, 35 min @ 100V, and stained with SYBR gold

Figure 10: Protein purification profile of VA-Mms6, VA1 and VA2, $12.5 \%$ separating gel, ran @100V, Lane1) Protein ladder, Lane 2) VA-Mms6 Lane 3) VA1 and Lane 4) VA2 27

Figure 11: Western Blot Stained with anti-His antibody, Lane1) purified His-tagged VA-Mms6; Lane 2) purified His-tagged VA1; Lane 3) purified His-tagged VA2 ................................ 29 Figure 12: (a) SEM image of iron particles synthesized in the presence of VA-Mms6 (b) EDS of iron particles synthesized in the presence of VA-Mms6 30

Figure 13: (a) SEM image of iron particles synthesized in the presence of VA2 (b) EDS of iron particles synthesized in the presence of VA3 
Figure 14: (a) SEM image of iron particles synthesized in the presence of VA3 (b) EDS of iron

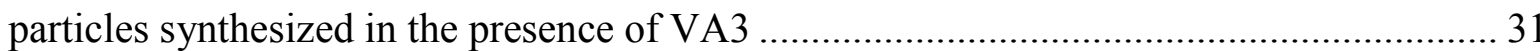

Figure 15: SEM Image of magnetite particles synthesized in presence of (a) PEG-VA2 (b) PEGVA3 32

Figure 16: TEM Images of magnetite particles synthesized in presence of (a) VA2 (b) VAMms6

(c) VA3

Figure 17: XPS spectra of magnetite particles synthesized in the presence of VA-Mms6, VA2, VA3 and XPS spectra of standard magnetite particles

Figure 18: Size distribution of particles synthesized in the presence of (a) VA-Mms6 (b) VA2 and (c) VA3.

Figure 19: AFM image of magnetite particles synthesized in the presence of (a) VA-Mms6 (b) VA2 (c) VA3.

Figure 20: MFM image of magnetite particles synthesized in presence of VA2 


\section{Chapter 1}

\section{Introduction}

\subsection{Biopolymers}

A biopolymer is formed via a biological route using sugars, amino acids or nucleotides as the building blocks. A few examples of biopolymers are cellulose, proteins and DNA. Genetically directed biosynthetic routes for producing protein-based polymers allow controlled spatial arrangement of macromolecules. Secondary structures and charges on the macromolecules can be controlled precisely through biosynthetic routes.

Protein folding, which plays a vital role in the functioning of proteins, can be controlled by monitoring amino acid sequence. Materials that have similar properties can be produced by mimicking naturally produced protein fibers such as silk, elastin and collagen. A specified polymer sequence is produced with high dependability when a gene encoding a target protein is translated into the protein sequence at the ribosome. ${ }^{1}$ Production of a polymer sequence is a two step process as shown in Figure 1. First, a particular DNA sequence is converted into a corresponding messenger RNA (mRNA) sequence. This step is known as transcription. The mRNA sequence serves as a template for protein synthesis. Decoding of mRNA is known as translation. Transfer RNA (tRNA) molecules play a central role in translation step. tRNA serves as a physical link between the mRNA and the growing polypeptide, and an informational link, ensuring that the polypeptide being synthesized has the proper amino acid sequence encoded by the mRNA. 


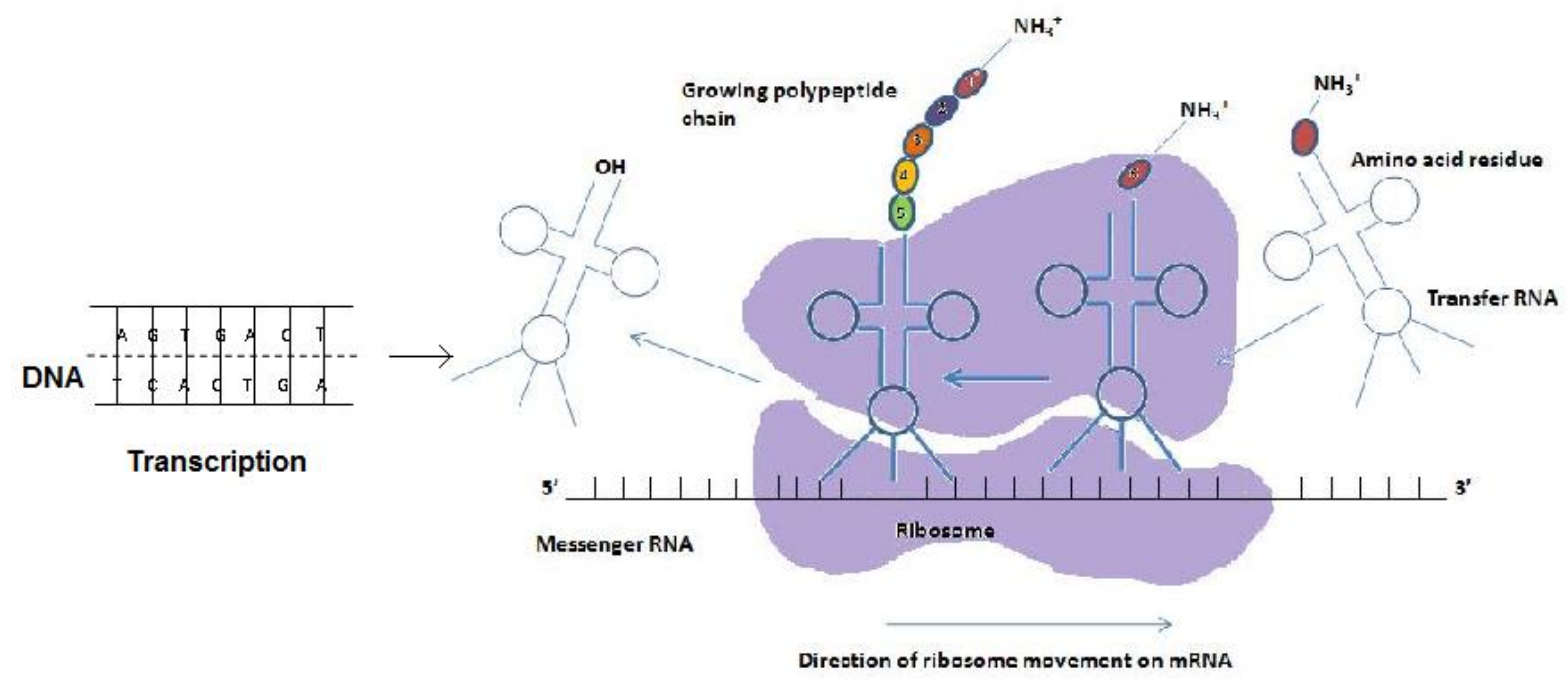

Figure 1: Schematic diagram of protein synthesis

\subsection{Examples of Biopolymers}

Silk is obtained from either silkworms or spiders and is one of the strongest natural protein fibers available. Because of the good mechanical and functional properties, silk is useful for biomedical applications. Silk fibroin from domestic silkworm Bombyx mori (B.mori) is used in medicine as sutures and artificial ligaments. ${ }^{2}$ For centuries, silk fibers have been used as sutures for wounds owing to their biocompatibility, low immunogenicity and high strength. Silk fibroins extracted from B.mori are spun from aqueous solution and have been used as a scaffold for human aortic endothelial cells and human coronary artery smooth muscle cells. In both cases, vascular tissues were formed in one week. ${ }^{3}$ Though silk is used extensively in many biomedical applications, the biggest obstacle is the production of silk in large quantities because of the dependence on spiders and silkworms to produce the material. Thus, a biomimetic approach has been used in which amino acid sequences from silk are used to produce silk-mimetic artificial proteins using genetic methods. ${ }^{2}$ Many attempts to design polymers similar to those of naturally occurring silks have been focused on silk protein sequences from B.mori silkworm and samia Cynthia ricini silkworm. The polyalanine and alanine-rich segments in the proteins from both spiders and 
silkworms are thought to play a vital role in the mechanical properties of silks. ${ }^{2}$ These silk proteins are mimicked and expressed in host cells like yeast to yield silk like materials.

Elastin is a protein that allows many tissues in body to return to their original shape after expansion. The main component of elastin is hydrophobic domain which contains valine and glycine in large quantity. ${ }^{2}$ The repeated sequence VPGVG mediates the mechanical properties of the protein and variations in this sequence have been used to produce elastin-like protein polymers. ${ }^{2}$ Elastin-like polypeptides (ELPs) exhibit an inverse temperature phase transition. Below their transition temperature ELPs are soluble in aqueous solutions; however, the proteins collapse through hydrophobic interactions at temperatures greater than the transition temperature. Elastin-like polypeptides (ELPs) are used in drug delivery systems. Elastin-like polypeptides (ELPs) coupled to drugs, which exhibit a transition temperature between body temperature and the temperature in a locally heated region, can effectively be used in treatment of solid tumours. ${ }^{4}$

The above example shows the use of genetically directed techniques to produce protein-based materials. Similarly, these techniques can be extended further to produce molecules that mimic proteins involved in the formation of nanoparticles in magnetotactic bacteria. To understand the mechanism of magnetite formation in bacteria, several proteins tightly bound to bacterial magnetite proteins in M. magneticum AMB-1 were isolated by Arakaki and co. ${ }^{5}$ They used these proteins to nucleate the formation of magnetite extracellularly.

\subsection{Synthesis of Iron Nanoparticles via chemical routes}

Iron particles can be synthesized using chemical and biological routes. The following are a few examples of chemical routes to synthesize iron nanoparticles.

\subsubsection{Co-precipitation}

Crystalline iron particles can be synthesized from aqueous $\mathrm{Fe}^{2+} / \mathrm{Fe}^{3+}$ salt solutions by the addition of a base in inert atmosphere. ${ }^{6}$ The mean size of particles can be controlled by adjusting 
the $\mathrm{pH}$ and ionic strength of the precipitation medium. As the $\mathrm{pH}$ and ionic strength of medium increases, size of the particles decreases. ${ }^{7}$ The chemical composition of the surface and the electrostatic surface charge of the particles are influenced by $\mathrm{pH}$ and ionic strength of medium. In this method, it is possible to control the mean size of particles between $2 \mathrm{~nm}$ to $15 \mathrm{~nm}$. Owing to the huge surface-area to volume ratio, nanoparticles produced by co-precipitation tend to aggregate in solution in order to reduce their surface energy. ${ }^{8}$

\subsubsection{Thermal Decomposition}

Thermal decomposition of organometallic compounds (metal acetylacetonate, where the metals can be $\mathrm{Fe}, \mathrm{Mn}, \mathrm{Co}, \mathrm{Ni}$ or $\mathrm{Cr}$ ), in the presence of surfactants results in formation of magnetic nanocrystals. ${ }^{9}$ The control over the size and morphology of the particles depends upon the initial ratio between organometallic compounds, surfactants and solvent. Based on the pyrolysis of metal fatty acids (decanoic acid, lauric acid, myristic acid, palmic acid, oleic acid, stearic acid) in non-aqueous solutions, a decomposition method was followed by Peng and co-workers to synthesize magnetic oxide nanocrystals. ${ }^{10} \mathrm{Fe}_{3} \mathrm{O}_{4}$ nanocrystals over a size range of 3-50 nm were synthesized. Variation in the reactivity and concentration of the precursors can be used to control the size and morphology of nanocrystals. The reactivity was adjusted by changing the chain length and concentration of fatty acids; the shorter the chain length, the faster is the reaction rate. Hyeon and co-workers used nontoxic iron (III) chloride and sodium oleate to prepare monodisperse iron oxide nanoparticles. ${ }^{11}$ Depending on the decomposition temperature, particle sizes over a range of $5 \mathrm{~nm}-22 \mathrm{~nm}$ were formed. The nanoparticles formed by this method were dispersible in organic solvents, but in most biomedical applications water dispersible magnetic particles are desirable. ${ }^{9}$ One of the disadvantages to thermal decomposition is the time consuming and complicated process.

\subsubsection{Two phase method (Microemulsion)}

In order to obtain metal oxide nanoparticles, microemulsions such as water in oil are being investigated. A microemulsion is a thermodynamically stable isotropic dispersion of two immiscible liquids, where an interfacial film stabilizes the microdomain of one or both liquids. ${ }^{12}$ 
These microemulsions coupled with surfactants offers a distinct environment for the growth of nanoparticles. ${ }^{9}$ Carpenter et al. prepared metallic iron particles coated by a thin layer of gold. ${ }^{13}$ Coating protects the iron core from oxidation, making them applicable in biomedicine. The nanoparticles formed via microemulsion methods are difficult to scale-up and the properties of the particles are adversely affected by the residual surfactants. Nanoparticles synthesized by this method have particle sizes which vary over a wide range; moreover the yield of nanoparticles is very low when compared to thermal decomposition and co-precipitation. Synthesis of nanoparticles at industrial level requires high temperatures, $\mathrm{pH}$, and pressures and results in formation of toxic byproducts. Table 1 gives an overall comparison of the synthetic methods used for synthesis of nanoparticles.

Table $1^{9}$ : Comparison of Synthetic Methods

\begin{tabular}{|l|l|l|l|l|l|}
\hline Synthetic Method & Synthesis & $\begin{array}{l}\text { Reaction } \\
\text { Temp }\left[{ }^{\circ} \mathbf{C}\right]\end{array}$ & $\begin{array}{l}\text { Reaction } \\
\text { Period }\end{array}$ & $\begin{array}{l}\text { Shape } \\
\text { Control }\end{array}$ & Yield \\
\hline Co-Precipitation & $\begin{array}{l}\text { Very simple, ambient } \\
\text { conditions }\end{array}$ & $20-90$ & Minutes & Not good & High \\
\hline Thermal deposition & $\begin{array}{l}\text { Complicated, inert } \\
\text { atmosphere }\end{array}$ & $100-320$ & $\begin{array}{l}\text { Hours- } \\
\text { days }\end{array}$ & Very good & High \\
\hline Microemulsion & $\begin{array}{l}\text { Complicated, ambient } \\
\text { conditions }\end{array}$ & $20-50$ & Hours & Good & Low \\
\hline
\end{tabular}

\subsection{Biomineralization}

Because of the high temperature and time often required to make nanoparticles, biomineralization is a new technique being investigated. Biomineralization refers to processes by which organisms make minerals. Until the early 1980s biomineralization was known as "calcification" due to the predominance of biologically formed calcium-containing minerals. Over a period of time, many more biogenic minerals were discovered and a more specific term "biomineralization", was given. A high degree of control is exerted by organisms over mineral formation in biomineralization. A few examples of biominerals are carbonates, phosphates, oxides, and fluorides. ${ }^{14,15}$ Biomineralization processes can be classified into two groups based on 
their degree of biological control. In the 1980's Lowenstam introduced these processes as "biologically induced mineralization" (BIM) and "biologically controlled mineralization" $(\mathrm{BCM})$. There is a marked difference between the two processes in terms of the functionality of the biomineralized particles. Particles that are produced by BIM have no function except that they might act as a form of protection from different environments, whereas particles produced by BCM have high degree of crystallinity. Particles formed by BCM have definite shape and size which makes them useful in many biomedical applications. One of the best examples of BCM is the formation of magnetic nanoparticles in magnetosomes within the magnetotactic bacteria. Biomineralization of magnetite has also been found in algae, ${ }^{16}$ insects,${ }^{17}$ birds and even humans. ${ }^{18}$

\subsection{Magnetotactic Bacteria}

Magnetotactic bacteria are aquatic prokaryotes that can move under the direction of a local geomagnetic field. The term magnetotactic bacteria, was first cited in a publication in 1963 written by Salvatore Bellini. R.P. Blakemore observed that under the influence of a magnetic field, bacteria migrated from south to north, giving rise to the term magnetotactic. ${ }^{19}$ This behavior is attributed to the existence of cytoplasmic membrane vesicles termed „magnetosomes' which enclosed magnetite particles of uniform morphology. ${ }^{19}$ Different strains of magnetic bacteria show different migration patterns under local geomagnetic fields. Magnetic bacteria discovered in Northern Hemisphere migrate parallel to the magnetic field, show a northward migration under the influence of geomagnetic field, and are termed north-seeking (NS) magnetotactic bacteria. ${ }^{19}$ Magnetotactic bacteria discovered in southern hemisphere migrate antiparallel to the local geomagnetic fields, show a southward migration in the geomagnetic field, and are termed south-seeking magnetotactic bacteria. ${ }^{20}$ The magnetotactic bacteria discovered near equator were equally distributed south-seeking and north-seeking bacteria. ${ }^{21}$

After the discovery of the first magnetotactic bacterial strain, there were reports of magnetotactic bacterial strains from marine and fresh water. ${ }^{22,23,24}$ Magnetotactic bacteria have different cellular morphologies; they can be cocoid, rod-shaped, helical or multicellular". 22,25 Despite their diversity in cellular morphologies, several features are common in all strains. All magnetotactic 
bacteria possess magnetosomes and are motile. Magnetotactic bacteria are very sensitive to environmental oxygen concentration and most of them can only synthesize magnetosomes in very low oxygen concentrations. ${ }^{26}$ All magnetotactic bacteria reported to date are gram-negative bacteria. Gram-negative bacteria are those which do not retain the crystal violent dye in gram in the gram staining protocol.

Magnetotactic bacteria discovered to this point fall into one of the following categories: microaerophiles, anaerobic or both. ${ }^{25}$ In aqueous environments magnetotactic bacteria are found in great numbers in an oxic-anoxic transition zone (OATZ). Magnetotactic bacteria can synthesize magnetosomes only if low oxygen concentrations are present. In general, if the initial oxygen concentration in the atmosphere of cultures is higher than $6 \%$, these bacteria cannot synthesize magnetite. ${ }^{23}$

\subsubsection{Bacterial Magnetite Particles}

Magnetotactic bacteria produce two types of minerals; iron oxides and iron sulfides. The type of mineral biomineralized is dependent on the external environment in which bacteria survive. The magnetotactic bacteria that produce iron oxides biomineralize magnetite $\left(\mathrm{Fe}_{3} \mathrm{O}_{4}\right)$ and those that produce iron sulfides biomineralize greigite $\left(\mathrm{Fe}^{2+} \mathrm{Fe}^{3+}{ }_{2} \mathrm{~S}_{4}\right)$ and sometimes pyrites $\left(\mathrm{FeS}_{2}\right){ }^{27}$ Magnetite is found in bacteria from microaerobic fresh water and marine environments, whereas greigite is found in bacteria from marine environments only. First direct evidence of magnetite was found in 1979 by R.P.Blakemore when he isolated the first pure culture of magnetotactic bacteria, Magnetotactic Spirillium strain MS-1. ${ }^{23}$ With the help of Mossbauer spectroscopy, Frankel et al. concluded that the iron containing mineral present was $\mathrm{Fe}_{3} \mathrm{O}_{4}$. Magnetite particles so synthesized had high chemical purity and had an average size of $50 \mathrm{~nm} \cdot{ }^{24}$ Some magnetotactic bacteria synthesize both magnetite and greigite. ${ }^{25}$

All magnetosomes are of size $35-120 \mathrm{~nm}$ regardless of their composition. The morphologies of the crystals reported to date fall into three categories; cuboidal, elongated prismatic and tooth-, bullet-or arrowhead-shaped. ${ }^{25}$ Particles of size range $35-120 \mathrm{~nm}$ formed stable single magnetic domain (SMD) particles. The magnetic moment is the net sum of moments of individual crystals 
in the chain. Magnetite particles within SMD range are permanently magnetic and their magnetic moment remains stable under ambient conditions. ${ }^{28}$ Particles whose size is less than $35 \mathrm{~nm}$ tend to be super paramagnetic and their net moment approaches zero. Particles with size greater than $120 \mathrm{~nm}$ are non-uniformly magnetized as multiple magnetic domains are formed. The magnetostatic interactions between particles results in the formation of a permanent magnetic dipole. A cell requires twenty $50 \mathrm{~nm}$ magnetosomes to have sufficient magnetic dipole moment for orientation along geomagnetic field. ${ }^{26}$ The magnetite particles which are synthesized are aligned in chains, and these chains act as compass needles and help in migration of magnetotactic bacteria. ${ }^{25}$

Synthesis of bacterial magnetosomes is a multistep process and involves - 1) magnetosome vesicle formation 2) iron uptake into the cell and then into the magnetosome vesicle and 3) magnetite or greigite biomineralization. ${ }^{5}$ Synthesis of magnetite particles involves three stages: First, ferric ions are taken up by the cell through a specific iron transport and then reduced to ferrous ions and transported into magnetosome vesicles. Second, ferrous ions are reoxidized to ferric ions and form hydrous ferric oxides. Third, one-third of ferric ions in ferric oxides are reduced into ferrous ions forming magnetite particles with defined morphology. ${ }^{29,25}$ Different strains adopt different routes to transport iron into vesicles. In the Magnetospirillum Magneticum strain AMB-1, iron is transported in the form of Fe (II). ${ }^{30}$ Figure 2 shows the schematic mechanism of iron uptake in Magnetospirillum Magneticum strain AMB-1.

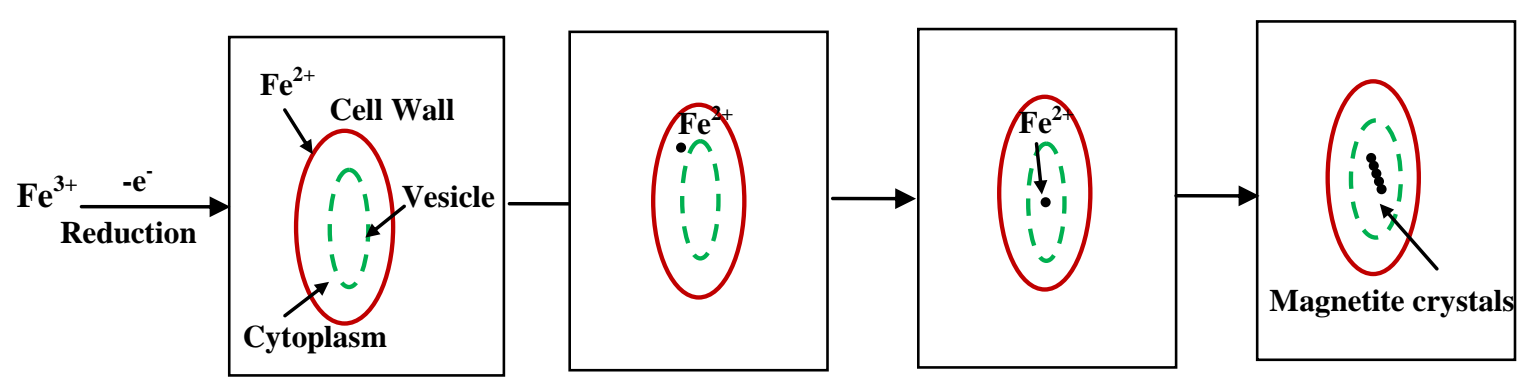

Figure 2: Schematic diagram of iron uptake mechanism in Magnetospirillum Magneticum strain AMB-1 (FRAMES 1-4)

First iron is reduced from ferric to ferrous at cell wall. Next, $\mathrm{Fe}^{+2}$ is transported to cytoplasm (Frame2) and then into vesicle (Frame 3) where it is finally oxidized to form magnetite particles 
(Frame 4). In Magnetospirillum Magneticum strain MS-1 Fe (II) is transported with the aid of siderophores. $^{31}$ In the Magnetospirillum gryphiswaldense strain, MSR-1, iron is taken in the form of Fe (III) without the aid of siderophores. ${ }^{25,32}$

\subsubsection{Magnetosome}

Magnetosomes are cell organelles with the magnetite crystal inside and an outer cover of a lipid bilayer membrane. The membrane is made up of phospholipids and has a similar composition as the cytoplasmic membrane. ${ }^{28,25,33}$ The term ,magnetosome' was first used by Balkwill et al. to describe "the electron-dense particles and their associated bounding layers in magnetotactic bacteria". ${ }^{33}$ Individual magnetosomes are linked to form chains, and they are attached to inner cytoplasmic membrane of the cell.

In 1988, Gorby et al. characterized the magnetosome membrane for the first time. ${ }^{34}$ The components of magnetosome membrane are mainly phospholipids, fatty acids and some proteins that were similar to those observed in cytoplasmic membrane. Although the composition of a magnetosome membrane is similar to cytoplasmic membrane, there was no clear evidence of the formation of magnetosome until 2006. ${ }^{35}$ In 2004, Komeili et al. showed the existence of magnetosome vesicles prior to magnetite formation in Magnetospirillum magneticum strain AMB-1, and protein MamA was required for their activation. ${ }^{36}$ Deletion of the mama gene, a gene encoding MamA, resulted in shorter magnetosome chains being synthesized inside the cells. Komeili proposed two possible functions of the protein MamA in magnetosome formation: 1) it may be involved in magnetosome assembly, 2) it may be used by magnetotactic bacteria to control the number of magnetosome vesicles they synthesize. In 2007, Komeili et al. studied the molecular mechanism of magnetosome formation in Magnetospirillum magneticum strain AMB$1 .^{28}$ Magnetosome formation involves three steps: invagination of cytoplasmic membrane to form magnetosomes, assembly into a chain templated by proteins Mamk and MamJ, and transport of iron into vesicles and synthesis of magnetite crystals with definite shape and size, which is initiated by Mms6. ${ }^{25,28}$ 


\subsubsection{Bacterial Biomineralization Protein-Mms6}

There are some proteins that are specific to the membrane and are responsible for magnetite crystal growth. One such protein Mms6 was first reported by Arakaki et al who characterized a number of proteins in Magnetospirillum magneticum strain AMB-1. Mms5, Mms7, Mms 13 were few other proteins that were isolated and characterized. ${ }^{5}$ All these proteins have a hydrophobic $\mathrm{N}$-terminal region and a hydrophilic C-terminal region. The most interesting conclusion from this report is that magnetite nanoparticles with similar morphology to bacterial magnetite particles can be synthesized in vitro in the presence of purified recombinant Mms6 expressed in E.coli. Figure 3 shows the electron micrographs of magnetic particles synthesized in presence and absence of Mms6. ${ }^{5}$
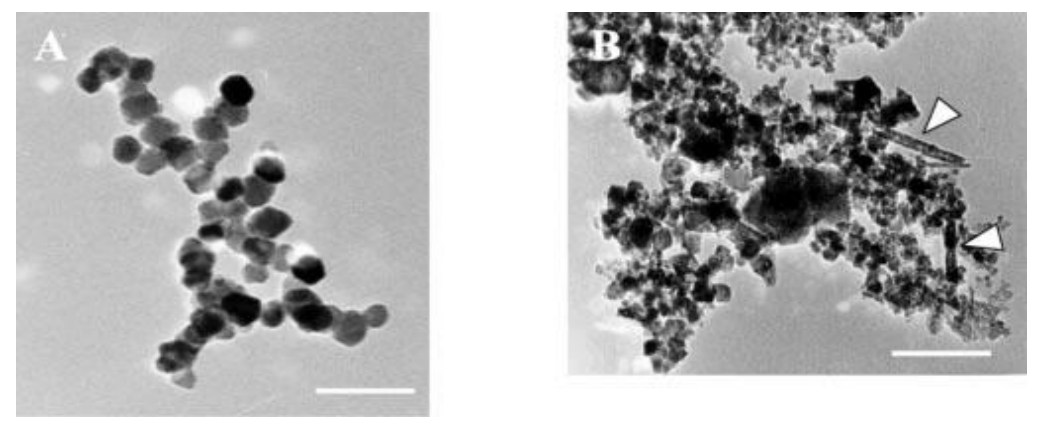

Figure $3^{5}$ : A) iron crystals in presence of Mms6 B) iron crystals in absence of Mms6

Iron produced in the presence of Mms6 showed cuboidal morphology, with size ranging from 20 to $30 \mathrm{~nm}$ (Figure 3A), whereas the magnetic particles produced in absence of Mms6 were nonhomogeneous in size (1-100nm) (Figure 3B). In 2007, Prozorov et al. reported magnetization measurements and structural characterization of magnetite nanoparticles synthesized in presence of recombinant Mms6. ${ }^{37} \mathrm{BSA}$, ferritin and Lcn2 were used as controls to compare magnetite particles synthesized in presence of proteins with different iron binding properties. These reports showed that magnetite particles with uniform morphology can only be synthesized in presence of recombinant Mms6. ${ }^{37}$

Prozorov et al. reported the synthesis of cobalt ferrite nanocrystals in the presence of HistidineMms6 (His-Mms6) and its C-terminus. ${ }^{38}$ They covalently attached His-Mms6 to self-assembling 
polymers to act as a template for synthesizing cobalt ferrite nanocrystals. Alternatively cobalt ferrite nanocrystals were synthesized by attaching C-terminus of Mms6 to self-assembling polymers. Complex magnetic crystalline nanomaterials of particle size $40-100 \mathrm{~nm}$ were produced , and these sizes with high degree of crystanility are difficult to produce using conventional techniques. The hydrophilic C-terminal region of Mms6 contains amino acid residues with either hydroxyl or carboxyl groups. The Figure 4 shows amino acid sequence of Mms6.

\section{AKTGVATAVAAPAAPANVAAAQGAGTKVALGA GKAAAGAKVVGGTIWTGKGLGLGLGLGLGAWG PIILGVVGAGAVYAYMKSRDIESAQSDEEVELRDALA}

Figure 4: Amino acid sequence of Mms6 deduced from the DNA sequence.

Arakaki et al. proposed that Mms6 may act as a template for magnetic nanoparticles synthesis and control the morphology of magnetite particles formed. ${ }^{5}$ The exact role of Mms6 in magnetite crystal formation remains still unclear.

\subsection{Applications of Magnetic Nanoparticles}

No matter the method of synthesis, the magnetic nanoparticle has a number of potential applications. Magnetic nanoparticles are widely being used for cell separation, ${ }^{39}$ automated DNA extraction, ${ }^{40}$ drug delivery and targeting ${ }^{41}$ and magnetic resonance imaging. ${ }^{8}$ Nontoxicity, biocompatibility and injectability are the important properties of magnetic particles which make them potential candidates for application in medicine. Magnetic cell separation has been carried out using antibodies that bind to proteins. DNA extraction is an important technique for DNA sequencing, and an automated DNA extraction process is useful in clinical fields. DNA can be separated from cell contaminants and debris by using magnetic particles. Use of magnetic particles over conventional separation methods reduces use of chemicals and increases the ease of separation of DNA. ${ }^{40}$

Chemotherapeutic drugs are non-specific and this nature makes them disadvantageous for various tumor treatments. Instead of attacking the tumor cells they also attack normal, healthy 
cells. Use of magnetic nanoparticles as carriers for cytotoxic drugs increases the uptake of drug at the target site. Therapeutic compounds are attached to biocompatible magnetic nanoparticles and high magnetic fields are used to guide the drug to tumor locations. ${ }^{41}$ Magnetic particles are attracted to higher magnetic flux density and this feature is used in drug targeting. Currently, magnetic nanoparticles are being used as contrast agents for magnetic resonance imaging. Figure 5 is a schematic illustration of the therapeutic strategy using magnetic nanoparticles. Magnetic particles can be used for diagnosis as well as cancer therapy simultaneously. Use of magnetic nanoparticles is slowly increasing in many fields.

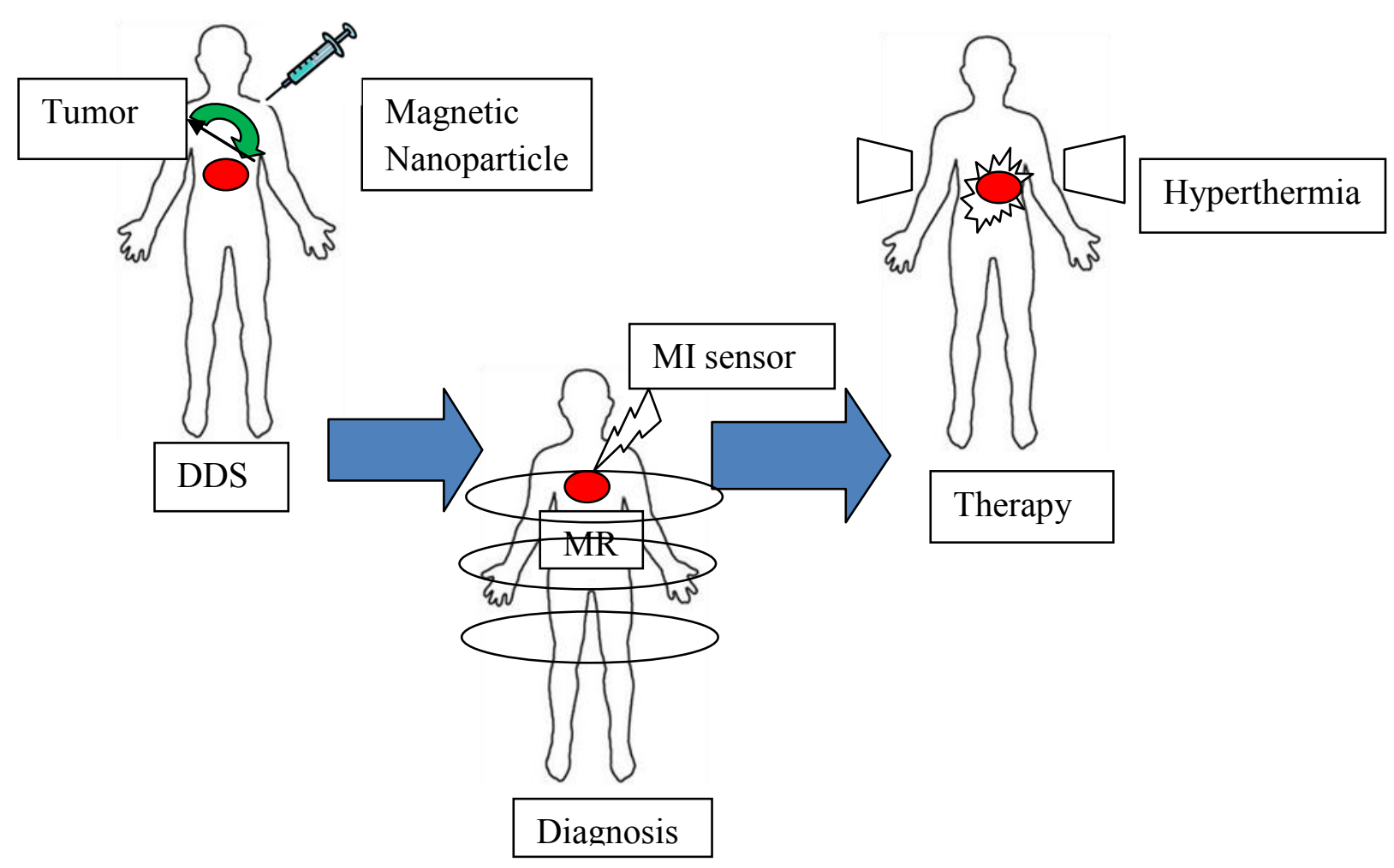

Figure $5^{41}$ : Functionalized magnetic nanoparticles accumulate in the tumor tissues via the drug delivery system (DDS). Magnetic nanoparticles can be used as a tool for cancer diagnosis by magnetic resonance imaging (MRI). Hyperthermia can be induced using alternating magnetic fields.

With these applications, synthesizing particles of specific size and shape by methods conducive for subsequent biomedical use is of great importance. 


\subsection{Purpose of Study}

It is clear that protein mediated synthesis of magnetic nanocrystals is a potential route for synthesis of well defined nanoparticles. Nanoparticles can be produced extracellularly, by making use of bacterial mineralization proteins against conventional chemical routes which often involve high temperatures and pressures. One such protein, Mms 6, isolated from the strain Magnetospirillum magneticum strain AMB-1 showed the ability to bind iron to produce homogeneous magnetic nanoparticles. Binding of iron was attributed to the presence of hydroxyl and carboxyl groups present in the $\mathrm{C}$-terminal hydrophilic region. The amino acid residues that possibly bind iron in Mms 6 sequence are bolded.

\section{Mms 6 GAVYAYGKSRDIESAQSDEEVELRD}

Serine(S), aspartic acid (D), glutamic acid (E) and tyrosine (Y) are the amino acid groups with functional groups hydroxyl and carboxyl, their structures are given in Table 2.

Table 2: Amino acids and their Structure

\begin{tabular}{|ll|l|}
\hline \multicolumn{2}{|c|}{ Amino Acid } & Structure \\
\hline Serine $\left(\mathrm{C}_{3} \mathrm{H}_{7} \mathrm{NO}_{3}\right)$ & & \\
\hline $\begin{array}{l}\text { Aspartic } \\
\left(\mathrm{C}_{4} \mathrm{H}_{7} \mathrm{NO}_{4}\right)\end{array}$ & Acid & \\
\hline $\begin{array}{l}\mathrm{Glutamic}^{2} \\
\left(\mathrm{C}_{5} \mathrm{H}_{9} \mathrm{NO}_{4}\right)\end{array}$ & Acid & \\
\hline Tyrosine $\left(\mathrm{C}_{9} \mathrm{H}_{11} \mathrm{NO}_{3}\right)$ &
\end{tabular}

The following sets of sequences were designed as variations in amino acids in Mms 6. VA1 has only hydroxyl groups(S, Y), VA2 has only carboxyl groups (D, E), and VA3 has combination of both hydroxyl and carboxyl. 
The above sequences are designed in order to compare with the sequence that is available from literature. Table 3 shows the newly designed peptides.

Table 3: Designed Peptides

\begin{tabular}{|l|l|}
\hline VA1 & GAVYAYGKSRSIYSAQSYSSVSLRY \\
\hline VA2 & GAVDADGKERDIDEAQEDEEVDLRD \\
\hline VA3 & GSEDAYGSYDESYDEQSEDYESYYS \\
\hline
\end{tabular}

The project addressed in this proposal involves inspecting the relative ability of functional peptides to bind iron by changing the amino acid sequence and most importantly to see whether there is a change in the shape of crystals formed with different peptide functionality. ${ }^{39}$ The three sequences were designed to test to what extent carboxyl and hydroxyl functional groups play a role in binding iron. 


\section{Chapter 2}

\section{Materials and Methods}

Production of protein polymers via biologically directed methods helps to create molecules with well defined sequences and functionality. These properties cannot be controlled in chemically synthesized molecules. A cloning strategy (Figure 6) for production of protein polymers is employed. Figure 6 shows how an insert is cloned and expressed in DNA plasmids to produce amino acid polymers.

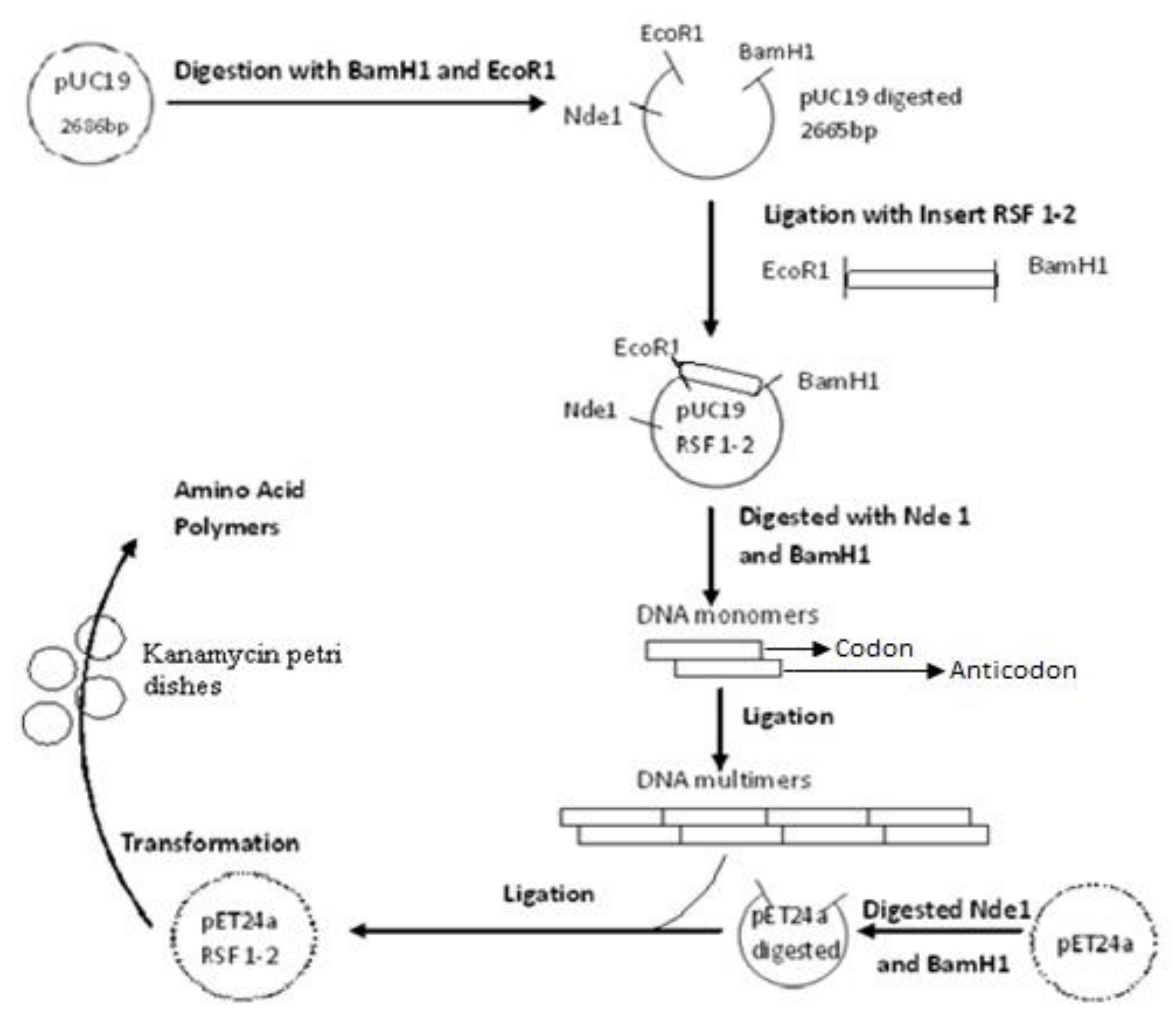

Figure 6 : Cloning strategy used for synthesis of amino acid

\subsection{Materials}

E.coli plasmids pUC19, pET19b and pET24a were purchased from Invitrogen (Carlsbad, CA). Restriction endonucleases were obtained from MBI Fermentas (Hanover, MD), and New 
England Biolabs (Beverly, MA). Oligonucleotide and plasmid purification kits and nickelcheleated sepharose resin were obtained from Qiagen (Valencia, CA). General reagents for protein expression and purification were purchased from Sigma (St. Louis, MO) and Fisher Scientific (Fairlawn, NJ). All inserts in initial phase of research were obtained from Invitrogen, while altered pJ414express, pJ201, and pJ241 were obtained from DNA 2.0 (Menlo Park, CA).

\subsection{Design of New Plasmids and Ongoing Research Work}

The oligonucleotide sequence of $\mathrm{Mms}^{12}$ described by Atsushi Arakaki et al. was modified as VAMms6. Other sequences were designed by replacing amino acids in Mms6 with hydroxyl and carboxyl amino acids to test how functionality differences affect binding of iron and nucleation of magnetic nanoparticles. These three sequences, VA1, VA2, and VA3 were designed for comparison with the control VAMms6. Figure 7 shows the sequences. Change in the sequences may alter the binding of iron to the peptides formed. VA1 contains functionality of hydroxyl groups from the side chains of serine (S) and tyrosine(Y). VA2 contains only carboxyl functional groups i.e. aspartic acid (D) and glutamic acid (E). VA3 contains both hydroxyl and carboxyl functional groups. These designed sequences were ordered in the cloning plasmids pJ201 or pJ241 from DNA 2.0. The inserts were designed with BamH1 and HindIII ends to ensure a proper ligation of the inserts into the expression plasmid pET24a. The DNA was received as $2 \mu \mathrm{g}$ of dry DNA and a stab culture in NEB-10 Beta cells. Cell stocks were made from the stab culture by streaking on plates with solid media containing kanamycin, matching the antibiotic resistance of $\mathrm{pJ} 201$ and $\mathrm{pJ} 241$.

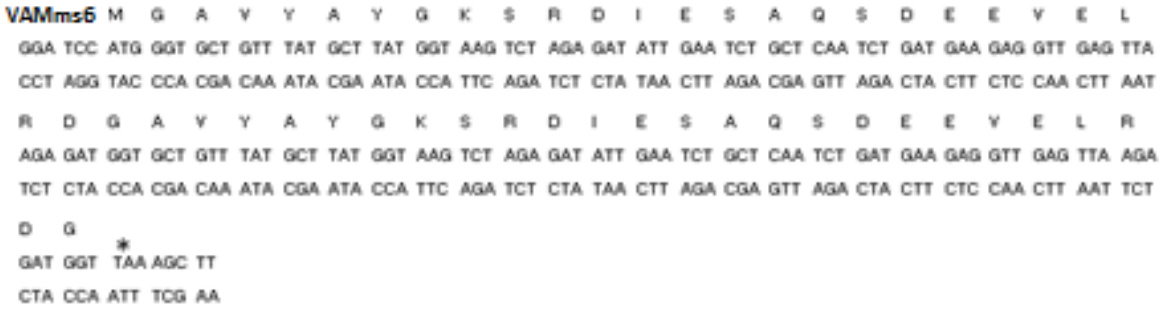




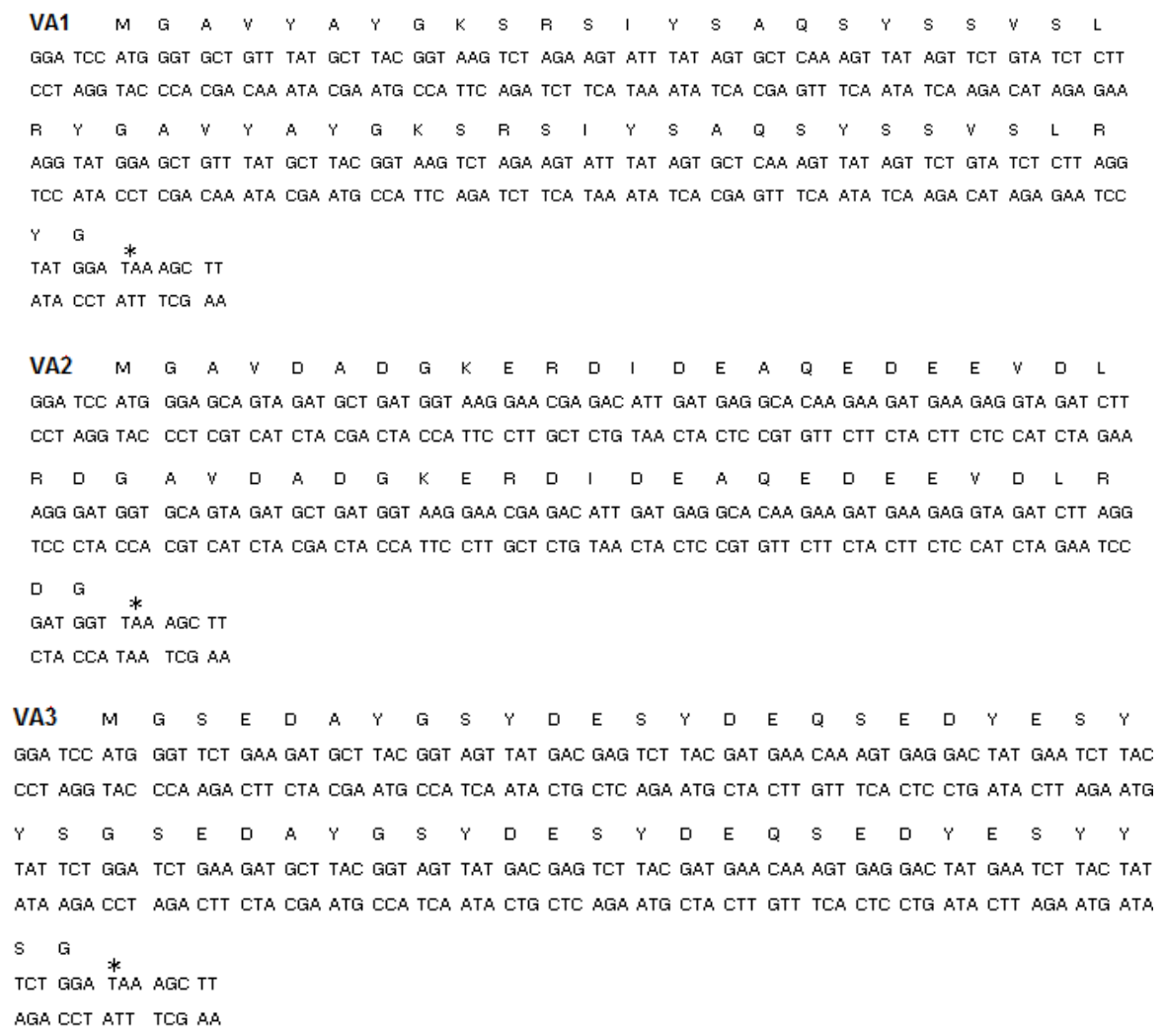

Figure 7: DNA sequence of new designed inserts with BamH1 and HindIII ends (* denotes stop codon)

\subsection{New Expression Construction}

The cloning plasmids were digested with enzymes BamH1 and HindIII for 30 min at $37^{\circ} \mathrm{C}$ in an incubator. The inserts were purified via $1 \%$ agarose gel electrophoresis. The expression vector pET24a was also digested with enzymes BamH1 and HindIII for $30 \mathrm{~min}$ at $37^{\circ} \mathrm{C}$ in an incubator. pET24a was dephosphorylated via treatment with CIP and purified using nucleotide removal kit. The inserts VAMms6, VA1, VA2 and VA3 were then ligated into pET24a. The ligated mixture

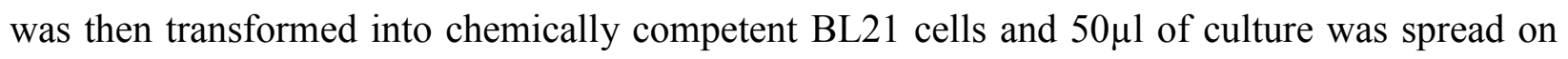
plates with solid media containing ampicillin and chloramphenicol antibiotics. These plates were incubated overnight at $37^{\circ} \mathrm{C}$ in an incubator.

The peptide sequences of VAMms6, VA1 and VA2 were ordered in expression vector pJ414. These sequences were ordered to eliminate the steps of ligation of insert into the expression plasmid. DNA was received as $2 \mu \mathrm{g}$ of dry DNA and a stab culture in NEB-10 Beta cells. Cell 
stocks of VAMms6, VA1, and VA2 were made from the stab culture by streaking on plates with solid media containing ampicillin. Dry DNA was suspended in $20 \mu 1$ of sterile water. DNA was transformed into chemically competent BL21 cells. The cells were spread onto petri dishes with solid media containing ampicillin and chloramphenicol antibiotics. These plates were incubated overnight at $37^{\circ} \mathrm{C}$ in an incubator. Single colonies were obtained from the petri dishes and put into $5 \mathrm{ml}$ cultures of liquid media. Culture tubes were shaken and placed in an incubator overnight at $37^{\circ} \mathrm{C}$. Cell stocks of VAMms6, VA1, and VA2 in BL21 cells were made for future use in peptide expression. $50 \mathrm{mg}$ of peptide VA3 was ordered from (Genscript, NJ). VA3 was ordered to carry out co-precipitation reaction with iron solution and analyze the particles formed under a Transmission electron microscopy (TEM).

\subsection{Protein Expression}

Cells from the cell stock of VAMms6, VA1 and VA2 in BL21 cells were used to inoculate a 50 $\mathrm{ml}$ starter culture in 2xTY media containing ampicillin $(200 \mu \mathrm{g} / \mathrm{ml})$ and chloramphenicol $(35 \mu \mathrm{g} / \mathrm{ml})$. Starter culture was shaken in an incubator overnight at $37^{\circ} \mathrm{C} .500 \mathrm{ml}$ of $2 \mathrm{xTY}$ media was inoculated with $10 \mathrm{ml}$ of the starter culture and $500 \mu \mathrm{l}$ of each antibiotic ampicillin and chloramphenicol. This culture was shaken in an incubator at $37^{\circ} \mathrm{C}$ until the optical density measured at $600 \mathrm{~nm}\left(\mathrm{OD}_{600}\right)$ reached a value of to $0.8 \pm 0.1$. At that point, protein expression was induced by the addition of $500 \mu \mathrm{l}(0.41 \mathrm{M})$ of isopropyl- $\beta$-D-thiogalactopyranoside (IPTG) and the cultures were grown for 4 more hours. After addition of IPTG, OD of samples was taken every one hour. At the end of 4 hours, cells were harvested by centrifugation (7000rpm, 15min), the supernatant was discarded, and the cell pellets were resuspended in $8 \mathrm{M}$ Urea Buffer at $\mathrm{pH} 8$ $\left(1 \mathrm{~g}\right.$ cell $/ 5 \mathrm{ml}$ of buffer) and stored in $-20^{\circ} \mathrm{C}$ freezer. The samples that were collected during protein expression were also centrifuged and the cell pellets were resuspended in TE Buffer.

\subsection{Protein Purification}

The suspended cell pellets in $8 \mathrm{M}$ urea buffer were thawed before sonication. Sonication was performed for 50 seconds with 2 seconds pulse on and 10 seconds pulse off. The cells were then centrifuged at $10000 \times \mathrm{g}$ for $30 \mathrm{~min}$ to remove the cell debris. At the end of the centrifugation, 
the supernatant was saved and the cell debris that precipitated at the bottom was discarded. The reserved supernatant was then incubated with Nickel-NTA resin for an hour at room temperature, shaking the beads continuously. The unbound proteins were separated from the nickel resin using a gravity-flow column. The flow-through of unbound molecules was saved for SDS-PAGE analysis. The nickel resin was washed with different $\mathrm{pH}$ buffers of $8 \mathrm{M}$ urea. First, a urea buffer of $\mathrm{pH} 6.3$ was used to wash the column. Then, the target proteins were eluted with urea buffers of $\mathrm{pH} 5.9$ and $\mathrm{pH} 4.5$. Optical density measurements were taken at $280 \mathrm{~nm}$ wavelength. All the flows through fractions from the wash steps were saved for future analysis by sodium dodecyl sulfate polyacrylamide gel electrophoresis (SDS-PAGE).

\subsection{SDS-PAGE}

Induction profiles were observed for all the peptides by running SDS-PAGE of samples that were collected during protein expression, before and after induction. Similarly protein purification profiles were also obtained via SDS-PAGE. The separating gels were made at $15 \%$ polyacrylamide concentration while the stacking gels were made at $6 \%$ polyacrylamide concentration. All the wash fractions from protein purification were loaded and the gel was run at $100 \mathrm{~V}$ for $90 \mathrm{~min}$. The gels were visualized using Coomassie blue stain. The gels were stained for $30 \mathrm{~min}$ and then destained overnight at room temperature.

\subsection{Amino Acid Analysis}

After purification of the peptides, the peptides were dialyzed and stored at $-80^{\circ} \mathrm{C}$. They were freeze dried, and the lyophilized material was sent out for amino acid analysis to confirm the presence of the desired peptides. All peptide samples were sent to the UC Davis Proteomics Core Facility for analysis. 


\subsection{Western Blots}

Western Blots were used to confirm the presence of the desired peptide with a His-tag. SDS-PAGE was run to separate the proteins by the length of the polypeptides. The proteins were transferred onto a PVDF membrane by electrophoresis for $1 \mathrm{~h} 15 \mathrm{~min}$ at $45 \mathrm{v}$. The membrane was washed in Tris-buffered saline (TBS) for 5 minutes and blocked using a blocking buffer purchased from Qiagen. The membrane was washed three times with TBS with Tween-20 (TBST) for 5 minutes a wash. The membrane was incubated with anti-His antibody at a dilution of 1:2000 in blocking buffer overnight. The membrane was washed three times with TBS-T. The first wash was for 5 minutes, the second and third was for 10 minutes and 15 minutes respectively. A chemiluminescent technique was used to detect the florescence. Chemiluminescent is a technique that involves incubation of the western blot with a substrate and in the process light is emitted due to a chemical reaction. The membrane was developed in $1 \mathrm{ml}$ of lumiglo for one minute. The florescence of the antibodies was detected by placing the membrane on a plastic film and exposing the film for two minutes.

\subsection{Synthesis of Magnetite nanoparticles using recombinant proteins}

Magnetite nanoparticles were synthesized via co-precipitation of $\mathrm{FeCl}_{2}$ and $\mathrm{FeCl}_{3}$ aqueous solutions in the presence of one of the recombinant proteins, VA-Mms6, VA1, VA2, or VA3. The following stoichiometric reaction is a balanced equation of magnetite formation.

\section{Equation 1: Stoichiometric equation of magnetite formation$$
\mathrm{FeCl}_{2}+2 \mathrm{FeCl}_{3}+8 \mathrm{NaOH} \rightarrow \mathrm{Fe}_{3} \mathrm{O}_{4}+8 \mathrm{NaCl}+4 \mathrm{H}_{2} \mathrm{O}
$$$$
4 \mathrm{Fe}_{3} \mathrm{O}_{4}+\mathrm{O}_{2} \rightarrow 6 \mathrm{Fe}_{2} \mathrm{O}_{3} \text {................ Undesired Reaction }
$$

The undesired reaction takes place if the reactants are exposed to atmosphere. The synthesis of magnetite nanoparticles was carried out in a glove box in order to provide the reaction media an inert nitrogen atmosphere. $100 \mu 1$ of $0.6 \mathrm{M} \mathrm{FeCl}_{3}$ and $\mathrm{O}_{3} 3 \mathrm{M} \mathrm{FeCl}_{2}$ were added to $10 \mu 1$ of peptide solution $(5 \mathrm{mg} / \mathrm{ml})$ in a $10 \mathrm{ml}$ round bottomed flask. All the solutions were degassed with argon for 3 minutes prior to their use. The reaction mixture was titrated slowly with $0.1 \mathrm{~N} \mathrm{NaOH}$ solution under constant nitrogen flow. As the titration progressed, the initial pale yellow solution 
slowly changed to brownish-yellow and finally to black. The formed iron particles were left to grow in sealed flasks for 7 days. At the end of 7 days, particles settled to the bottom of the flask and were further concentrated at the bottom using boron-neodymium magnet. The precipitate was then washed with degassed water and vacuum dried overnight at room temperature. Synthesis of magnetite was also carried out using polyethylene glycol (PEG) attached to the peptides VA2 and VA3. PEG was dissolved in $1 \mathrm{ml}$ of DMSO. To this VA2 or VA3 (1mg/ml), HBTU solution (a peptide coupling reagent) and N, N-Diisopropylethylamine (DIEA) were added. Definite volumes of HBTU and DIEA were added every 3 hours and the whole reaction mixture was stirred at room temperature overnight. The reaction mixture was dialyzed and stored in $-80{ }^{\circ} \mathrm{C}$ freezer. The coupled peptides (PEG-VA2 or PEG-VA3) were used to synthesize iron particles similar to the methods used with VAMms6, VA2 and VA3 to synthesize iron particles.

\subsection{Characterization of Magnetite Nanoparticles}

\subsubsection{Scanning Electron Microscopy}

Energy dispersive X-ray spectroscopy (EDS or EDX) is an analytical technique used for the elemental analysis or chemical characterization of a sample. The samples were imaged by scanning electron microscope and analyzed by EDS. The precipitate was dried on a copper tape stuck to an aluminum stub. The copper tape was used to increase conductivity and smoothness of surface. EDS was performed by Adrienne MacLeod McGraw. (WVU)

\subsubsection{Transmission Electron Microscopy (TEM)}

For TEM specimen preparation, the sample was first diluted with ethanol. After the solution was sonicated for about 10 minutes, a drop of the solution was transferred to a 200 mesh copper grid with carbon support and was then left to dry in ambient condition. TEM characterization was performed using a JEM-2000FX operating at 200kV. Selected area electron diffraction (SAED) was also performed on the samples. TEM was done by Dr. Chaoying Ni (University of Delaware). 


\subsubsection{X-ray Photoelectron Spectroscopy (XPS)}

XPS is a quantitative technique used to measure elemental composition, chemical state and electronic state that exists in a material. The XPS system used in these studies was a Physical Electronics 5700 ESCA system, equipped with both a standard Al/Mg x-ray source (energies of $1456 / 1253 \mathrm{eV}$ respectively) and a monochromatic Al source. The system was calibrated to the $\mathrm{Au} 4 \mathrm{f} 7 / 2$ peak to ensure linearity in the (binding) energy scale. The dried precipitate was placed on a silicon wafer and XPS was performed by Srikanth Raghavan. (WVU)

\subsubsection{Dynamic Light Scattering}

The size of particles synthesized were determined by dynamic light scattering (DLS; DLS-7000, Otsuka Electronics) for a sample dispersed in aqueous suspension after vortexing. The median diameter (number basis) was determined from the obtained size distribution. Dynamic light scattering was done with the help of Aaron Kessman.

\subsubsection{Atomic Force Microscopy (AFM)}

All atomic force microscopes have the same basic components: laser, cantilever, photodiode, controller, scanner, and computer. In AFM, the force transducer is a deflecting cantilever on which a sharp tip is mounted. The cantilever and tip assembly is scanned with respect to the surface to get the morphology of the surface. Using the laser light reflected from the cantilever back, a photodiode collects data on the deflection of the cantilever.

The system used for our measurements was calibrated using standards produced by Mikro-Mash. The standards used for this step were $20 \mathrm{~nm} \pm 1$ in height. The AFM was mounted on a Minus K vibration isolation table inside of a Herzan acoustic isolation hood. The precipitate was vacuum dried on silicon carbide wafers and AFM was performed. AFM was performed with the aid of Srikanth Raghavan (WVU). 


\subsubsection{Magnetic Force Microscopy (MFM)}

Magnetic force microscopy was performed on the samples. For the MFM, the tips have to be magnetic in nature. Magnetic nature enables the tip to detect any magnetic force from the sample onto the tip. All tips vibrate at a natural frequency called the resonance frequency. The thickness, length and width were typically $3 \mu \mathrm{m}, 225 \mu \mathrm{m}$ and $28 \mu \mathrm{m}$ respectively. The natural frequency or the resonance frequency of the tips was around $75 \mathrm{kHz}$. MFM instrument which was used for the purpose of this research is (manufactured by Agilent Technologies formerly Molecular Imaging, product name: $5500 \mathrm{SPM})$.

The height at which the tip is placed is called the "Interleave Height" or simply "Lift Height". Net magnetic force depends heavily on the tip-sample separation or the ,interleave height'. The interleave height used for this research was $100 \mathrm{~nm}$. It is important that the interleave height be greater than the highest features of the surface topography, if not the probe could actually crash into the sample surface. In order to maintain a constant interleave height throughout the experiment, the tip is usually pulled away from the sample by a value well above the interleave height and then brought back to the level of interleave. This particular value of pulling away from the sample is called as "Pullaway Height". The pullaway value used for this research was 300nm. MFM was performed with the help of Srikanth Raghavan. (WVU) 


\section{Chapter 3}

\section{Results and Discussions}

VAMms6 was ordered in expression vector pJexpress414, whereas VA1, VA2 and VA3 were ordered in cloning vector pJ201. The oligonucleotides VA1, VA2, and VA3 which are 170bp long, were digested from cloning vector pJ201 using the enzymes BamH1 and HindIII. Figure 8 shows the agarose electrophoresis gel of digested inserts.

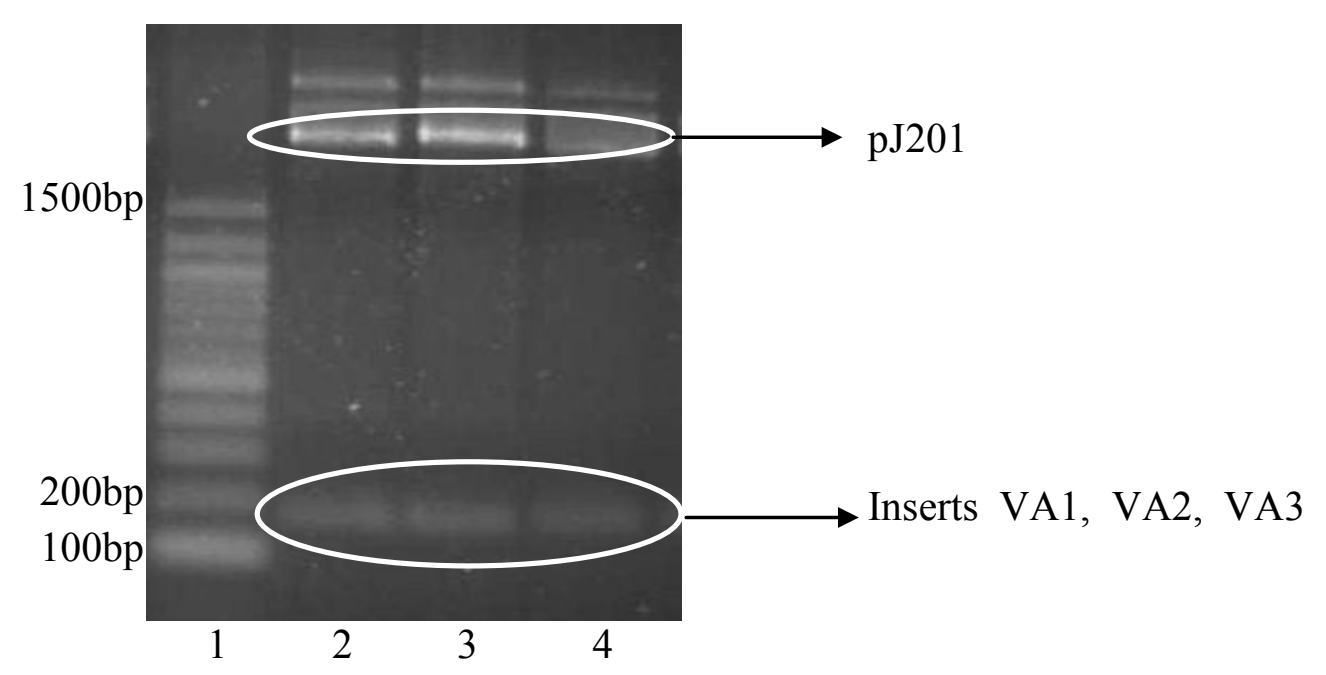

Figure 8: Lane 1) 100bp Ladder, Lane 2) VA1, Lane 3) VA2, Lane 4) VA3, 1.5\% gel, 40 min @ 100V, stained with SYBR gold

Two bands were observed in each lane numbered from 2 to 4 in Figure 8. One band was seen above 1500 base pair and other band was seen approximately at 200 base pairs as seen in comparison to the molecular weight ladder in lane 1 . These bands are at the expected molecular weight of the insert (170bp) and the remainder of the plasmid after digestion. The observed bands of inserts were cut from the agarose gel and purified using a Qiagen purification kit. In order to transfer inserts VA1, VA2 and VA3 into expression plasmid, pET24a was digested with BamH1 and HindIII, later purified using nucleotide removal kit. 
An agarose gel was run to determine the concentration of the insert and vector for subsequent calculations of ligating the inserts into the expression plasmid pET24a. Figures 9(a) and 9(b) are the images of concentration gel.

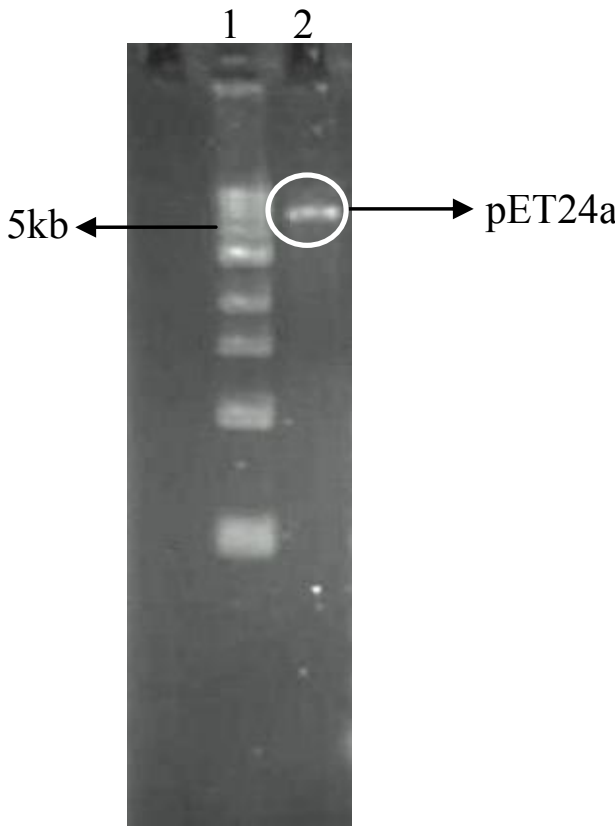

(a)

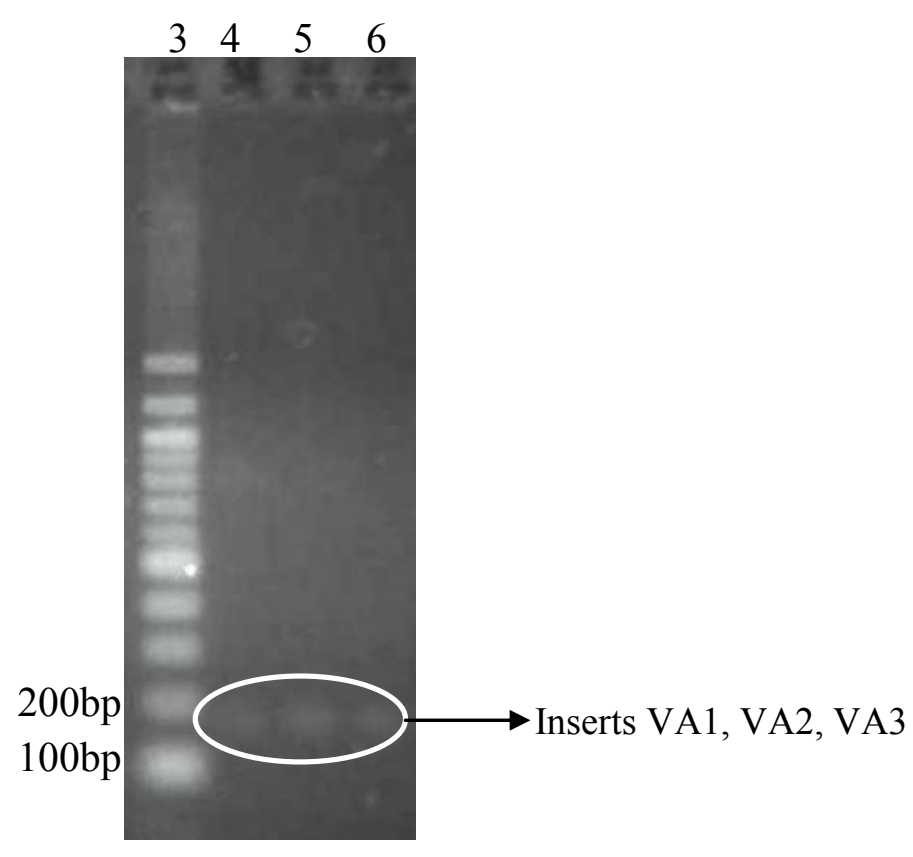

(b)

Figure 9 (a): Lane 1) 1 kb ladder, Lane 2) digested pET24a, (b) Lane 3) 100bp ladder, Lane 4) VA1, Lane 6) VA2, Lane 7) VA3, 1.5\% gel, 35 min @ 100V, and stained with SYBR gold

In comparison to the molecular weight ladders, a band was observed at about 5000bp as seen in Figure 9(a) and bands were observed at around 200 base pairs as seen in Figure 9(b). These bands were at the expected molecular weight of the digested pET24a (5140 bp) and the inserts $(170 \mathrm{bp})$. The concentrations of the DNA segments were determined by comparing the fluorescence intensity of the sample DNA with that of the band of comparable size in the 100bp DNA ladder, which contains a known concentration of DNA. Similarly, concentration of digested expression plasmid pET24a was determined by comparing the fluorescence intensity of digested pET24a with the fluorescence intensity of the closest corresponding band in the $1 \mathrm{~kb}$ DNA ladder. The relative intensity of the inserts was taken to be half of the intensity of $200 \mathrm{bp}$ marker, indicating a concentration of approximately $12 \mathrm{ng} / \mu 1$. The expression plasmid had the 
same intensity as that of $5 \mathrm{~kb}$ marker and therefore is at a concentration of approximately $42 \mathrm{ng} / \mu \mathrm{l}$. The volume of both insert and vector needed for a ligation was calculated using equation (2). ${ }^{42}$

$$
V_{v}=\frac{T}{\left(\frac{V_{c} \times I_{l} \times I_{r}}{I_{c} \times V_{l}}\right)+1} ; \quad I_{v}=T-V_{v}
$$

where, $\mathrm{T}$ is the volume of total ligating solution, $\mathrm{V}_{1}$ is the vector length, $\mathrm{V}_{\mathrm{c}}$ is the vector concentration, $V_{v}$ is the vector volume, $I_{1}$ is the insert length, $I_{c}$ is the insert concentration, $I_{v}$ is the insert volume and $\mathrm{I}_{\mathrm{r}}$ is the required insert-to-vector ratio for ligation.

Ratios of 300:1 and 600:1 (insert:vector) were used for ligation of inserts into vector pET24a. The ligated DNA was transformed into BL21 cells but the ligations were unsuccessful as there were no colonies on petri dishes. The ligations proved futile and hence to eliminate the ligation steps, VA1 and VA2 were ordered in expression plasmids pJexpress 414.

\subsection{Protein Expression}

Cells from the cell stock of VAMms6, VA1 or VA2 in BL21 were used to inoculate a 50ml starter culture in 2 XTY media containing ampicillin $(200 \mu \mathrm{g} / \mathrm{ml})$ and chloramphenicol $(35 \mu \mathrm{g} / \mathrm{ml})$. A starter culture was shaken in an incubator overnight at $37^{\circ} \mathrm{C}$. Culturing media $(500 \mathrm{ml})$ was inoculated with $10 \mathrm{ml}$ of the starter culture and $500 \mu 1$ of each antibiotic ampicillin and chloramphenicol. Table 4 gives the optical density values measured at different times during expression. 
Table 4: Optical density values of pJexpress414-VAMms6, pJexpress414-VA1, and pJexpress414-VA2 expressed in BL21 strain

\begin{tabular}{|c|c|c|c|c|c|}
\hline $\begin{array}{l}\text { pJexpress414 - } \\
\text { VAMms6 (Time } \\
\text { in hours) }\end{array}$ & $\begin{array}{l}\text { Optical density } \\
\text { at 600nm (BL 21 } \\
\text { cells) }\end{array}$ & $\begin{array}{l}\text { pJexpress414 } \\
\text {-VA1 (Time in } \\
\text { hours) }\end{array}$ & $\begin{array}{l}\text { Optical density } \\
\text { at 600 nm (BL } \\
\text { 21 cells) }\end{array}$ & $\begin{array}{l}\text { pJexpress414 - } \\
\text { VA2 } \\
\text { in hours) }\end{array}$ & $\begin{array}{l}\text { Optical density } \\
\text { (Time 600nm (BL 21 } \\
\text { cells) }\end{array}$ \\
\hline 2.5 & 0.791 & 2.5 & 0.769 & 2.5 & 0.773 \\
\hline 3.5 & 1.19 & 3.5 & 1.52 & 3.5 & 1.55 \\
\hline 4.5 & 1.30 & 4.5 & 1.95 & 4.5 & 1.90 \\
\hline 5.5 & 1.73 & 5.5 & 2.05 & 5.5 & 2.10 \\
\hline 6.5 & 1.80 & 6.5 & 2.54 & 6.5 & 2.25 \\
\hline
\end{tabular}

*time points after 2.5, samples were diluted to determine the OD value. Values reported are corrected with the dilution factor $1 / 10$

The cells that were harvested after expression were purified under denaturing conditions. Purification under denaturing conditions involves a series of washes with $8 \mathrm{M}$ urea buffer at different $\mathrm{pH}$ values of $6.3,5.9$ and 4.5. The purified fractions were collected and analyzed on a SDS-PAGE gel. The gel was visualized using Coomassie blue staining. Figure 10 shows the elution samples of VAMms6, VA1 and VA2 respectively, after purification.

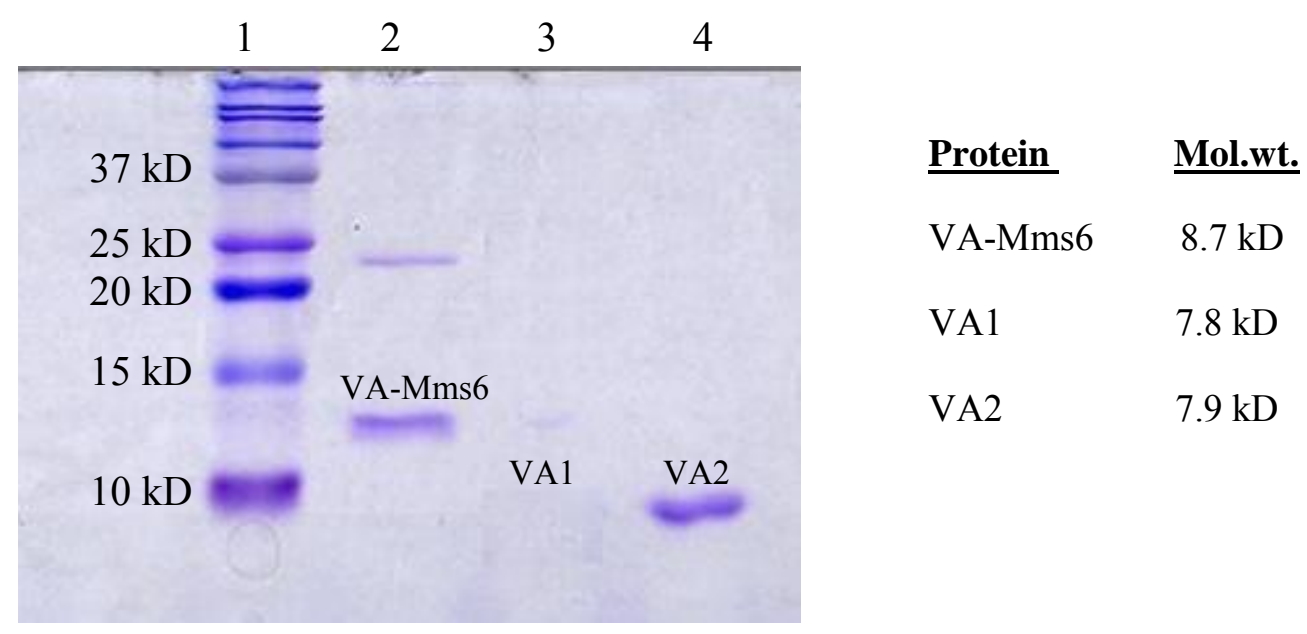

Figure 10: Protein purification profile of VA-Mms6, VA1 and VA2, 12.5\% separating gel, ran @100V, Lane1) Protein ladder, Lane 2) VA-Mms6 Lane 3) VA1 and Lane 4) VA2

Two bands were observed in lane 2, one between $10 \mathrm{kD}-15 \mathrm{kD}$ and the other between $20 \mathrm{kD}-25$ $\mathrm{kD}$ as compared to the molecular weight ladder in lane 1. VA-Mms6 (8.7 kD) is expected to run higher due to the presence of highly charged functional groups. A second band seen at around 
$20 \mathrm{kD}$ reveals the folding of peptide VA-Mms6. In lane 3 there were no bands. Repeated number of purifications did not yield VA1; reason being VA1 was not properly expressed. In case of VA2, as seen in lane 4, there was a single band seen at roughly $10 \mathrm{kD}$. This band is slightly higher than expected, owing to the presence of negatively charged carboxyl functional groups in VA2. This purification profile showed that VA-Mms6 and VA2 were reproducible whereas, VA1 cannot be expressed and hence is not used in further study.

\subsection{Amino Acid Analysis}

The results from amino acid analysis are shown in Appendix A. After purification and lyophilization, samples were sent out for amino acid analysis. The amino acid analysis was

performed by digesting the peptide with $\mathrm{HCl}$ and reducing the peptides to their amino acid components. The digested material was analyzed using chromatography. The result was reported in nmol/injection of each amino acid. Based on the amino acids present in the peptides, the percent content of each amino acid was compared to the expected percent. It is seen that the deviation of the observed results were less than $\pm 2 \%$ of the expected value. The observed and expected mole percentage of amino acids was in good agreement with the amino acid analysis of the peptides VA-Mms6 and VA2, indicating that proteins of interest had been produced. Amino acid analysis was done at UC, Davis CA in Proteomics Core Facility.

\subsection{Western Blot}

A western blot was run to detect proteins with His-tag. Western blot is an electrophoretic technique where the proteins are separated based on their charge and mass. Specific antibodies are used to detect the presence of specific proteins. A chemiluminescent detection method was carried out to visualize the proteins. Figure 11 shows the western blot image of VA-Mms6, VA1 and VA2. 


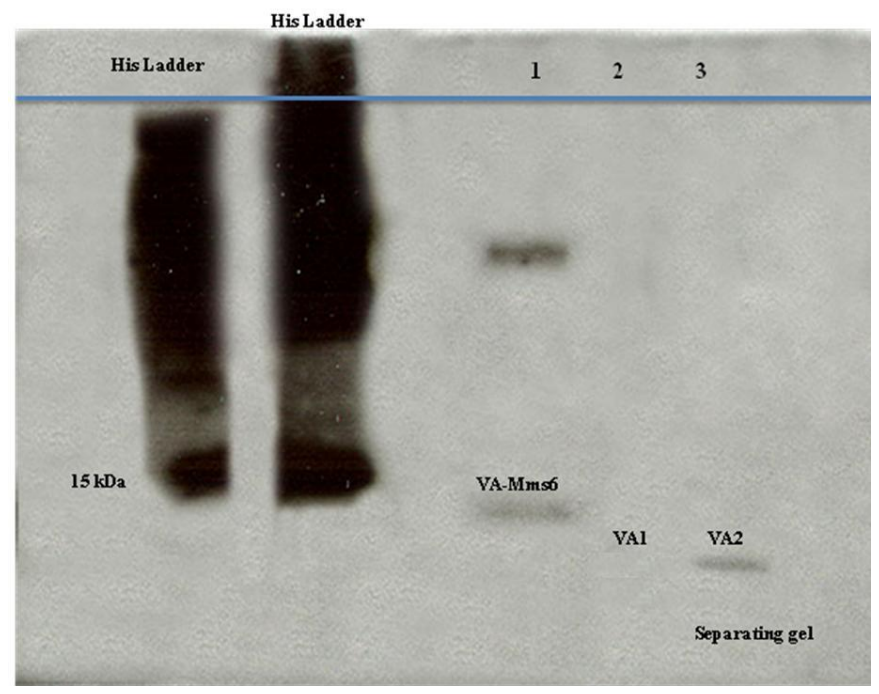

Figure 11: Western Blot Stained with anti-His antibody, Lane1) purified His-tagged VA-Mms6; Lane 2) purified His-tagged VA1; Lane 3) purified His-tagged VA2

The protein bands that were visible on the SDS-PAGE were also observed on the PVDF membrane at the same molecular weight, confirming the presence of proteins. For VA-Mms6 in lane 1, we observed a band at a higher molecular weight, which might be due to protein folding present in the VA-Mms6 peptide. As seen in lane 2, VA1 was not observed which is in consistent with the PAGE gel. A band was seen in lane 3 for VA2, confirming that the desired peptide was correctly expressed and purified. The His-ladder did not get resolved properly, because the ladder was not heated before loading into the wells. Changing the volume of ladder to be loaded and heating prior to loading might help in better resolution. Western Blot was done at Health Science Centre, WVU Morgantown WV with the help of Dr. Yogesh Kulkarni.

\subsection{Synthesis of Magnetite Nanoparticles}

To confirm that VA-Mms6, VA2 and VA3 can stimulate the formation of magnetite particles with defined structures, we have synthesized magnetite particles in the presence of VA-Mms6, VA2 and VA3. Figure 12(a) shows the SEM image and Figure 12(b) shows the EnergyDispersive Spectrum (EDS) of particles synthesized in the presence of VA-Mms6. 


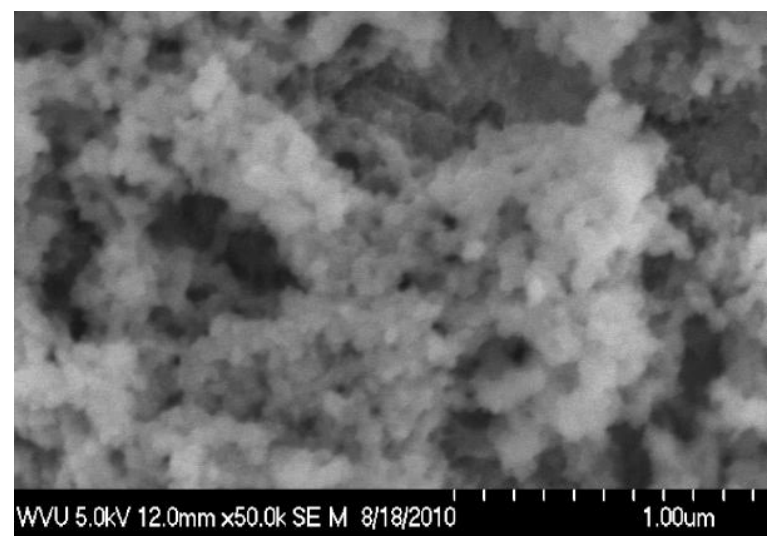

(a)

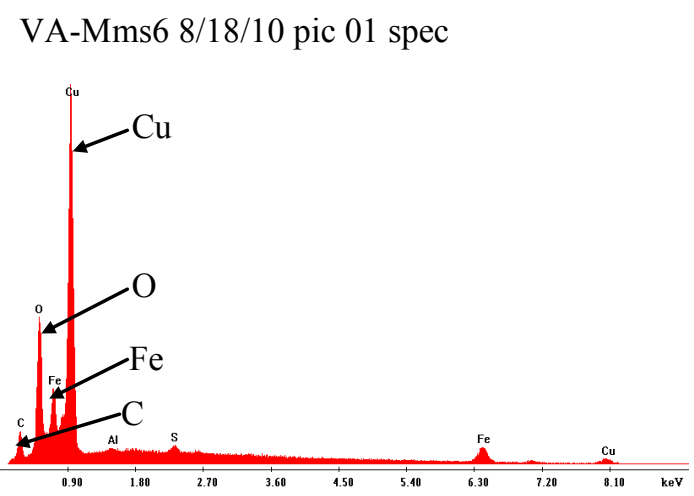

(b)

Figure 12: (a) SEM image of iron particles synthesized in the presence of VA-Mms6 (b) EDS of iron particles synthesized in the presence of VA-Mms6

The particles synthesized in the presence of VA-Mms6 were confirmed to be iron particles by performing EDS. The iron and oxygen peak seen in the Figure 12(b) can be related to the presence of iron oxide particles. A large peak of copper is seen as it was used as a surface to dry the particles and hence it is the background. Carbon peak in the spectrum comes from the backbone of the peptide. However, the particles were heavily aggregated as seen in the SEM image. The reason for the aggregation is due to the presence of high charge surface on the peptide that nucleates the formation of iron particles.

Figure 13(a) and Figure 13(b) show the SEM and EDS of particles synthesized in the presence of VA2. EDS analysis reveals the presence of iron particles. The peaks seen in Figure 13(b) can be attributed with the same reasoning as given for peaks in EDS in Figure 12(b) (above). 


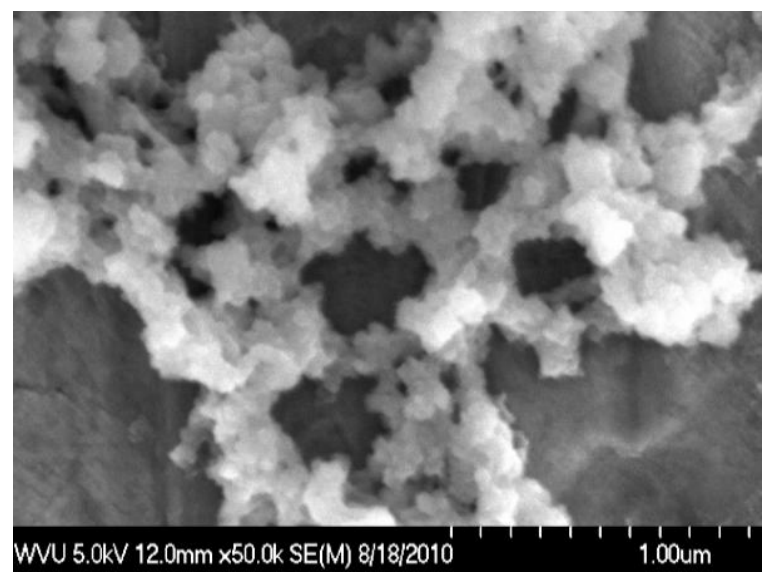

(a)
VA2 8/18/10 pic $01 \mathrm{spec}$

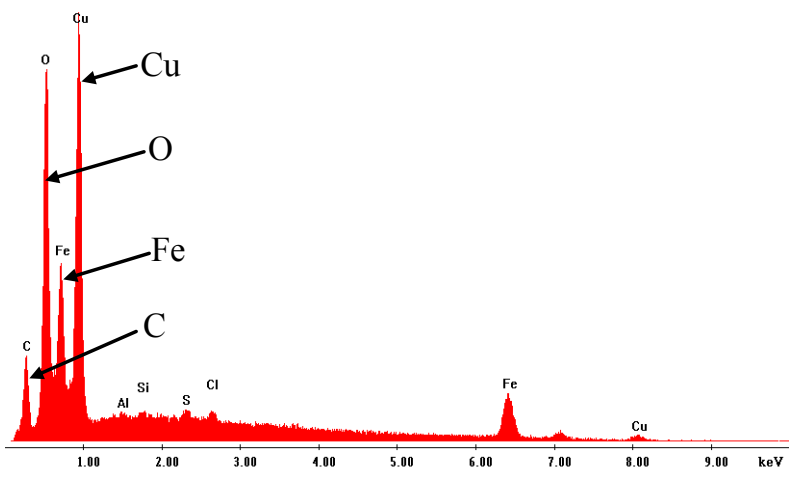

(b)

Figure 13: (a) SEM image of iron particles synthesized in the presence of VA2 (b) EDS of iron particles synthesized in the presence of VA3

Similarly, SEM and EDS of synthesized particles in presence of VA3 is shown in Figures 14(a) and $14(\mathrm{~b})$, respectively.

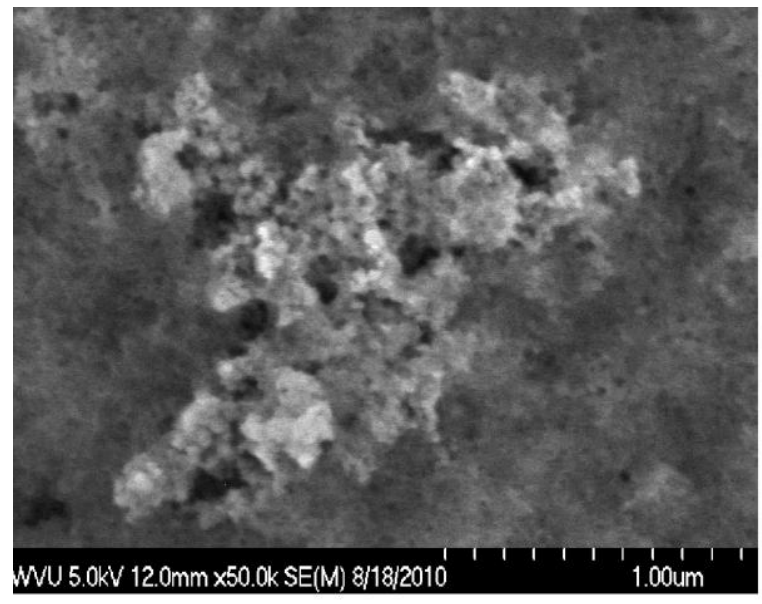

(a)
VA3 8/18/10 pic 01 spec

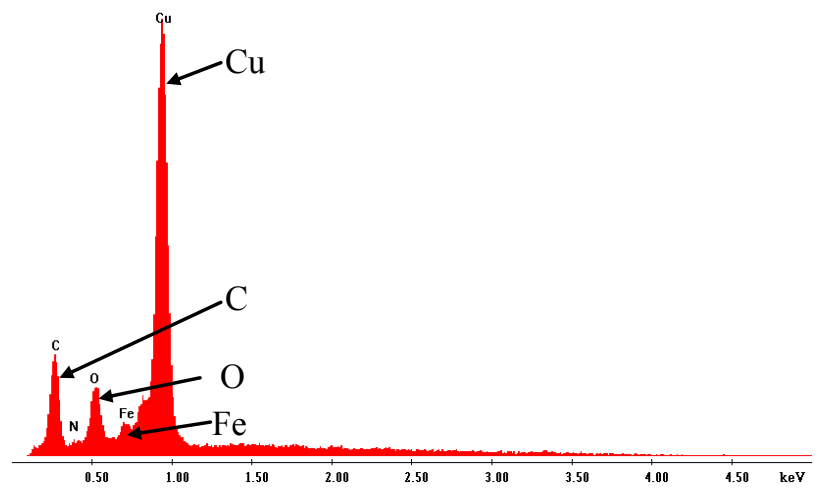

(b)

Figure 14: (a) SEM image of iron particles synthesized in the presence of VA3 (b) EDS of iron particles synthesized in the presence of VA3

Due to the presence of high-charge density on VA3 the synthesized particles were aggregating to a greater extent. EDS of the particles reveals that the synthesized particles in the presence of VA3 are iron particles. The same trend of iron, oxygen and copper peak was seen in Figure 14(b) as in Figure 12(b) and Figure 13(b). All the SEM measurements were performed by Adrienne McGraw (WVU). 
Magnetite particles were also synthesized using polyethylene glycol (PEG). Figure 15 shows the SEM image of magnetite particles formed in the presence of PEG-VA2 and PEG-VA3.

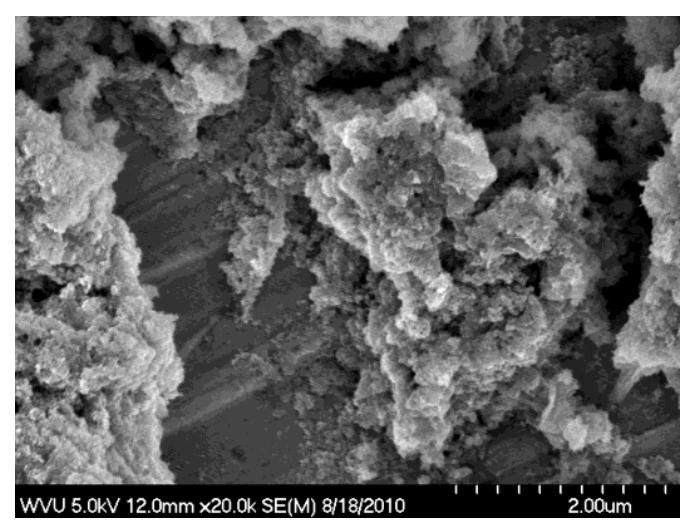

(a)

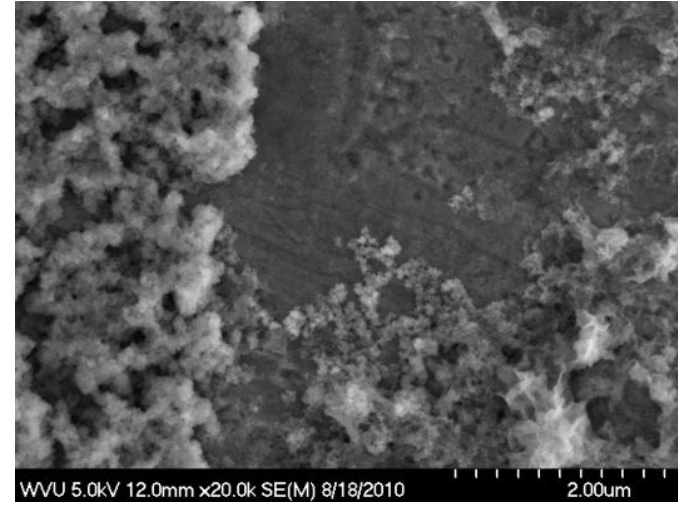

(b)

Figure 15: SEM Image of magnetite particles synthesized in presence of (a) PEG-VA2 (b) PEG-VA3

There was greater tendency in the aggregation of particles when biocompatible polymer like PEG was attached to the peptides VA2 or VA3 to synthesize iron particle, Figure 15 depicts the same tendency. Characterization of iron particles synthesized with PEG-VA2 or PEG-VA3 can be carried out as future work for further qualitative and quantitative details of iron particles.

\subsection{Transmission Electron Microscopy (TEM)}

There was a huge difficulty in looking at the particles through SEM for particle size ranging from 50 to $100 \mathrm{~nm}$, due to aggregation of particles. Due to the inherent limitation of SEM to provide only surface analysis, TEM was used to provide detailed sectional analysis in nanoscale, which can be used to study synthesized iron particles for present work.

Figure 16 shows the TEM images of iron particles synthesized by co-precipitation of $\mathrm{FeCl}_{2}$ and $\mathrm{FeCl}_{3}$. 


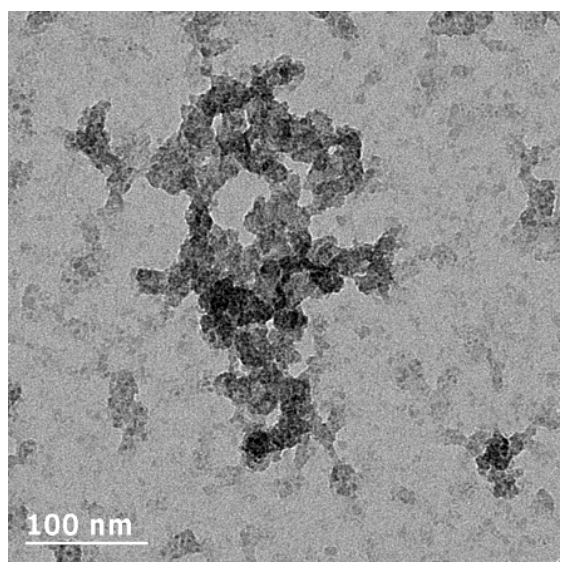

(a)

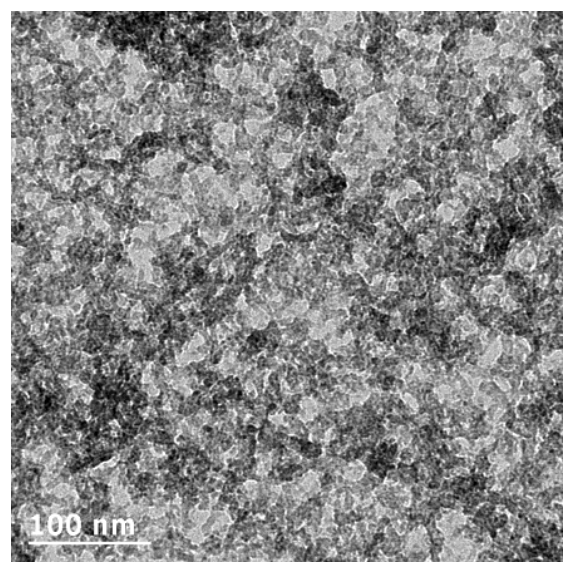

(b)

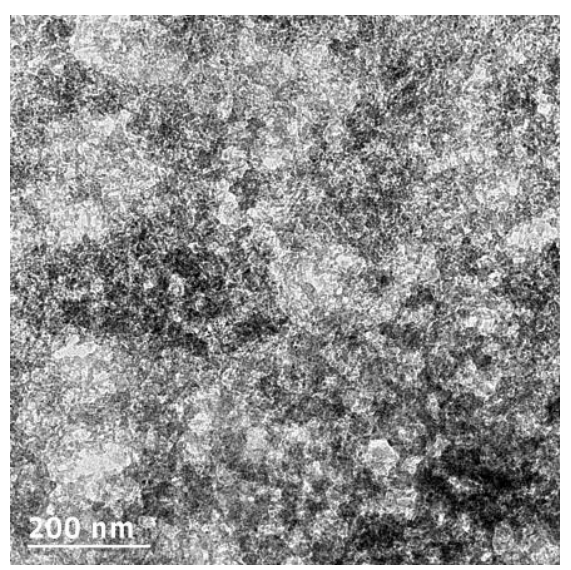

(c)

Figure 16: TEM Images of magnetite particles synthesized in presence of (a) VA2 (b) VAMms6 (c) VA3

The iron particles synthesized in the presence of VA2 (Figure 16a) were discrete, exhibiting a size range of $50 \mathrm{~nm}$ forming stable single magnetic domains. The iron particles exhibited a definite morphology. The iron particles synthesized in the presence of VA-Mms6 (Figure 16b) and VA3 (Figure 16c) were highly aggregated making it difficult to locate individual particles, due to this reason images of iron particles did not show a defined morphology in either of the case. VA2 has more number of carboxyl groups than VA-Mms6 and VA3. Discrete particles were seen when VA2 was used showing that the high charge of carboxyl groups was responsible in nucleating iron particles in size range of $50 \mathrm{~nm}$. Particles synthesized with the aid of VA2 were found to be similar in size and morphology with those produced by Arakaki et al. Visualization of particles synthesized with the aid of VA-Mms6 and VA3 was difficult. The sample preparation for TEM was done by Dr.Chaoying Ni. All the TEM measurements were performed by Dr. Chaoying Ni (University of Delaware). 


\subsection{X-Ray Photoelectron Spectroscopy}

XPS was run to determine the elemental composition and chemical state of the elements present in the sample. Figure 17 shows the XPS spectra of the synthesized iron particles in presence of VA-Mms6, VA2, VA3 and standard $\mathrm{Fe}_{3} \mathrm{O}_{4}$ respectively.

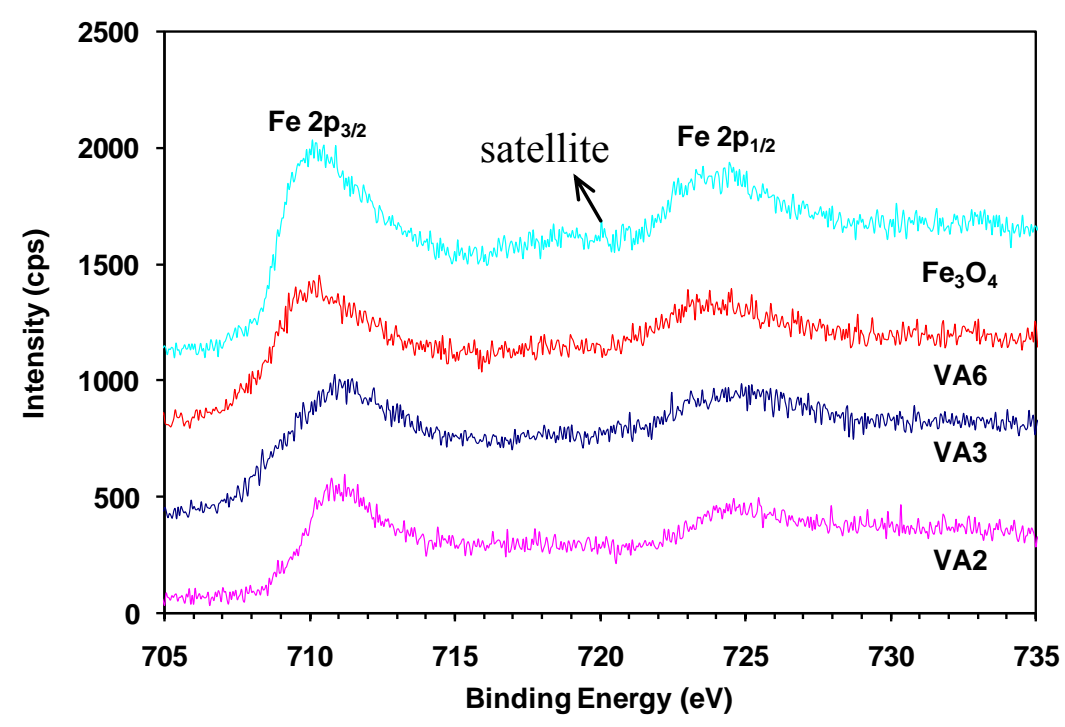

Figure 17: XPS spectra of magnetite particles synthesized in the presence of VA-Mms6, VA2, VA3 and XPS spectra of standard magnetite particles

XPS spectrum of individual samples is shown in Appendix B. A detail of the iron peaks (Fe $2 \mathrm{p} 1 / 2$ and $\mathrm{Fe} 2 \mathrm{p} 3 / 2$ ) can be seen in Figure 17. The 2p3/2 peak shows a binding energy with a $\mathrm{Fe}^{\mathrm{II}}$ component. In addition; in this case, the XPS analysis was very important in verifying the oxidation state of iron. The $\mathrm{Fe}^{\mathrm{II}} / \mathrm{Fe}^{\mathrm{III}}$ ratio, experimentally measured in different magnetite samples, ranged from 0.33 to 0.67 . In the XPS spectrum, the binding energy signals appears at $724.4 \mathrm{eV}$ and $711.0 \mathrm{eV}$, which are the 2p electron orbit of iron atom in $\mathrm{Fe}_{3} \mathrm{O}_{4}{ }^{43}$ In Figure 17 XPS spectra of magnetite particles synthesized in presence of VA-Mms6 closely matches to the standard magnetite particle spectra. The XPS spectra of particles synthesized in the presence of VA2 and VA3 have a slight shift in the binding energy signals when seen in comparison to the standard. The shift in the peaks is due to the presence of $\mathrm{Fe}^{+2}$ and $\mathrm{Fe}^{+3}$ in non-stoichiometric ratios. A satellite is seen in all the spectra most likely because of electron transfer from a ligand 
(oxygen) to a normally empty valence level in Iron. The XPS analysis confirmed that the synthesized oxide was magnetite and was successfully synthesized in the presence of peptides VA-Mms6, VA2 and VA3. However particles synthesized in presence of VA2 and VA3 showed non-stoichiometric ratios of iron in magnetite. XPS was done by Srikanth Raghavan (WVU).

\subsection{Dynamic Light Scattering (DLS)}

In order to determine the size of synthesized magnetite particles in the presence of peptides, dynamic light scattering was performed. Figure 18 shows the size distribution of synthesized magnetite particles.

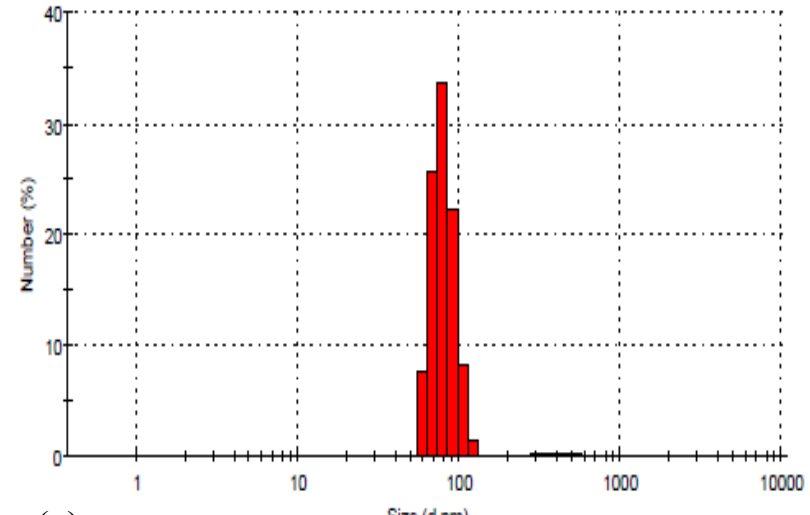

(a)

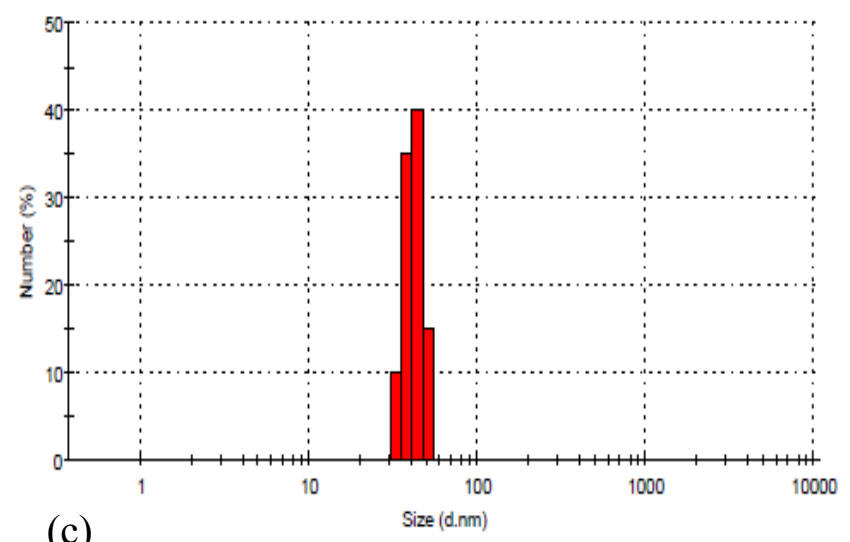

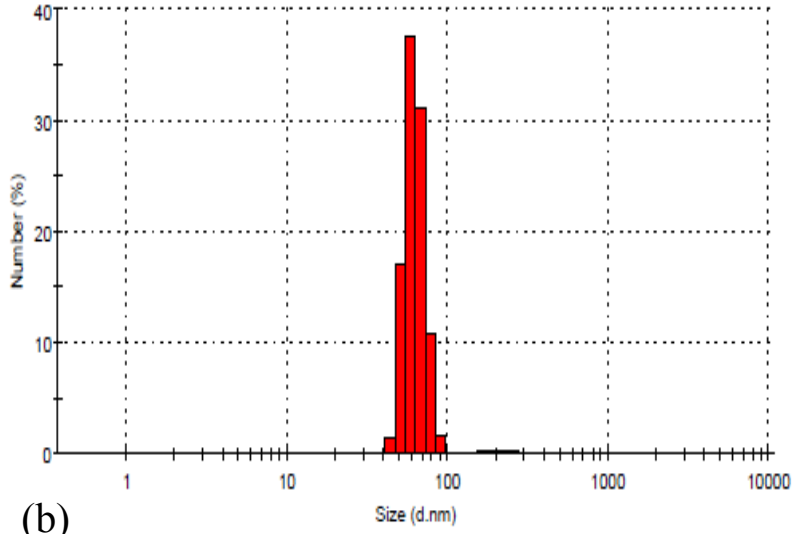

(b)

\begin{tabular}{|c|c|}
\hline \multicolumn{2}{|c|}{ Peak Diameter } \\
\hline VAMms6 & $88 \mathrm{~nm}$ \\
VA2 & $62 \mathrm{~nm}$ \\
VA3 & $41 \mathrm{~nm}$ \\
\hline
\end{tabular}

Figure 18: Size distribution of particles synthesized in the presence of (a) VA-Mms6 (b) VA2 and (c) VA3

Particles synthesized in the presence of VA-Mms6 had a maximum distribution at a peak diameter of 88nm. Particles synthesized in the presence of VA2 and VA3 showed maximum size distribution of particles at a peak diameter of $62 \mathrm{~nm}$ and $41 \mathrm{~nm}$ respectively. Particles of size 
range 35-120nm form stable single magnetic domains and the magnetite particles synthesized in the presence of all the peptides fall in this size range. Particles synthesized using Mms6 by Arakaki and et al. was of size range 30 to $40 \mathrm{~nm}$. Magnetite particles synthesized in the presence of VA2 and VA3 closely matches with those produced by Mms6. The size range of VA2 was around $40 \mathrm{~nm}$ when observed using a magnetic force microscopy against $60 \mathrm{~nm}$ seen using dynamic light scattering. A possible reason is that the individual particles located in the scan region of magnetic force microscopy were of order 40nm. Dynamic light scattering was done with the help of Aaron Kessman. (WVU)

\subsection{Atomic Force Microscopy (AFM)}

$\mathrm{Fe}_{3} \mathrm{O}_{4}$ particles were dried on a silicon carbide wafer; this wafer was analyzed using AFM to observe the surface for magnetite particles. Particles were scanned in an area of $5 \mu \mathrm{m} \times 5 \mu \mathrm{m}$. Figures 19(a), 19(b) and 19(c) show the AFM images of magnetite particles synthesized in presence of VA-Mms6, VA2 and VA3 respectively.

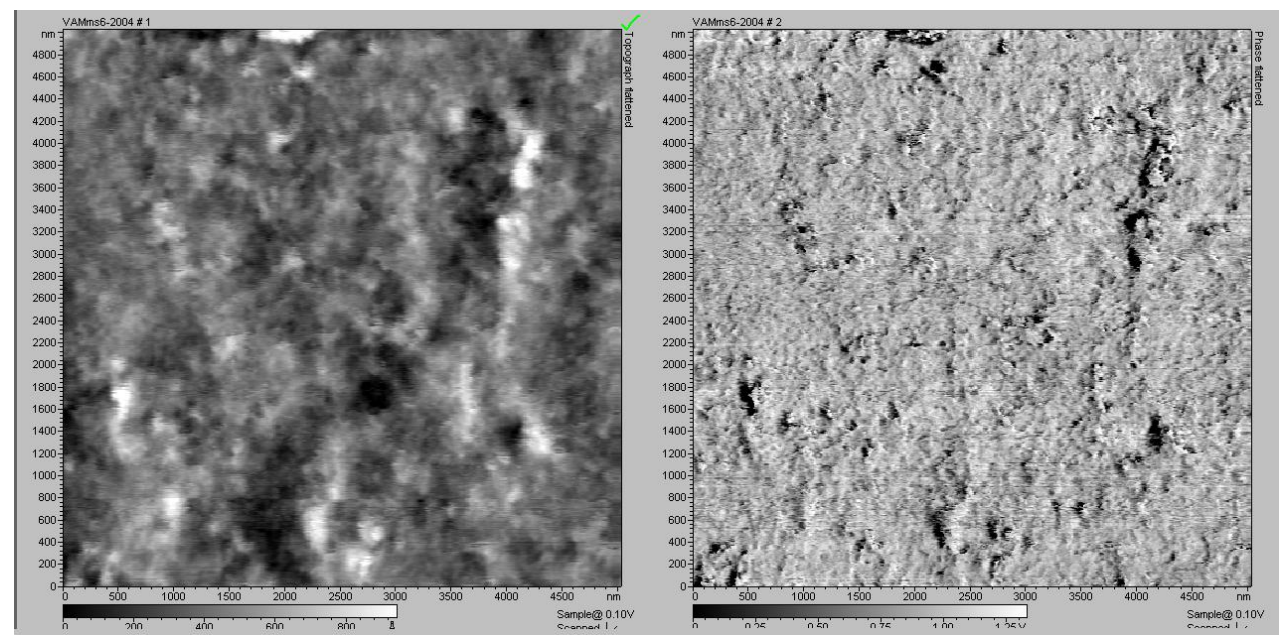

(a) 


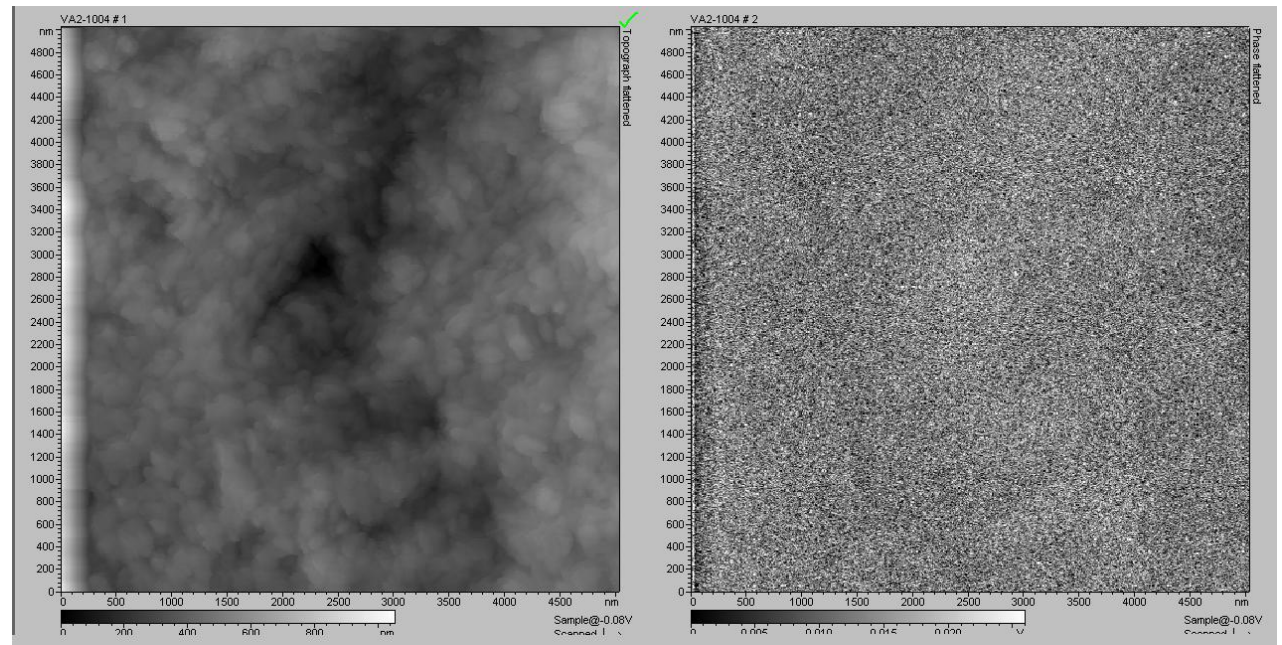

(b)

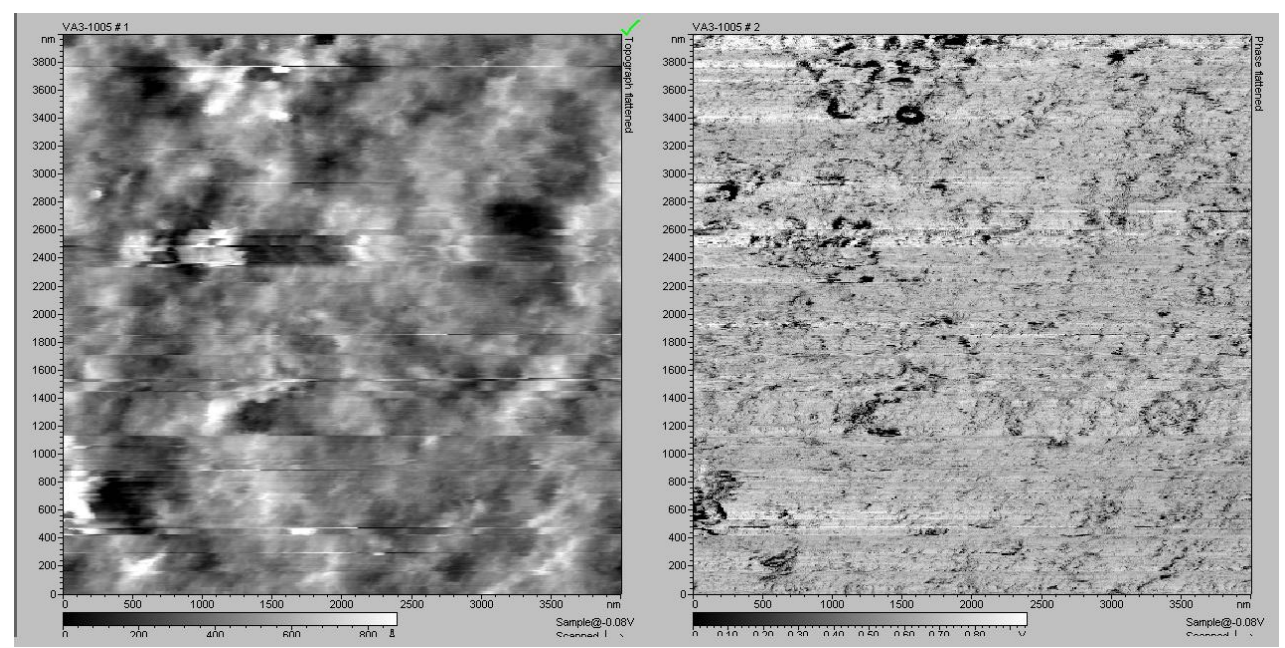

(c)

Figure 19: AFM image of magnetite particles synthesized in the presence of (a) VA-Mms6 (b) VA2 (c) VA3

The left half of each AFM image is the topography and the right half is the phase. The agglomeration of particles is seen in all the topography images. In case of magnetite particles synthesized in presence of VA-Mms6 they appeared more like a cloud whereas in presence of VA2 uniform size of particles is seen with defined morphology. In presence of VA3 magnetite particles are very difficult to locate individually. There was a difficulty in sample preparation as the particles agglomerated during drying. AFM was performed with the help of Srikanth Raghavan (WVU). 


\subsection{Magnetic Force Microscopy (MFM)}

Magnetic force microscopy was done on particles synthesized in presence of VAMms6, VA2 and VA3 in order to find magnetic domains. Figure 20 shows the MFM image of magnetite particles synthesized in the presence of VA2.

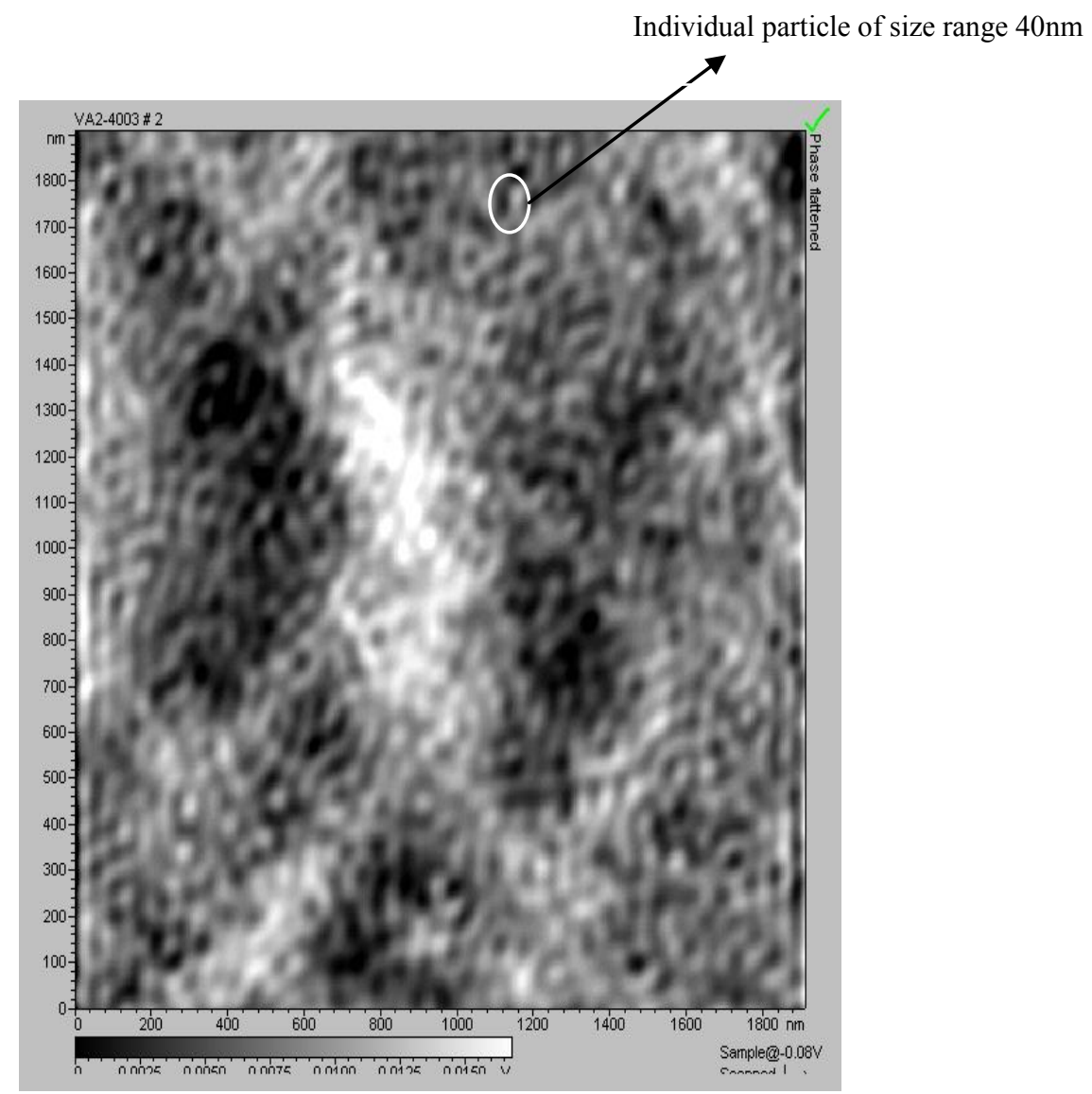

Figure 20: MFM image of magnetite particles synthesized in presence of VA2

The first part of the MFM analysis consisted in locating a region where individual particles can be seen in domains. In this region, lift mode MFM revealed that all the domains stay in different directions with defined parallel strips due to the anisotropy. Well-defined walls and domains shifts were interpreted as negative (repulsion) in bright regions, while positive (attraction) in dark regions. Domains formed in the magnetic field were measured in a range of $30-40 \mathrm{~nm}$ by the profile following transversal direction across the domains. 
Magnetic domains were seen only in the case of particles synthesized in presence of VA2 (Figure 20). This confirmed the magnetic nature of particles formed. The size range of particles $(40 \mathrm{~nm})$ observed falls in the region of particles with single magnetic domains. This is a slight decrease in the size of particles when seen against dynamic light scattering results for particles synthesized using VA2. In case of particles synthesized with the aid of VAMms6 and VA3, individual particles could not be located because of aggregation. Another possibility is that the polymer is covering the particles making it even more difficult for the magnetic interactions to be seen as an image. Care should be taken that the interleave height is small enough for the magnetic interactions between the tip and surface to be seen. Very small heights might crash the tip. So, an optimum interleave height of $100 \mathrm{~nm}$ should be maintained. MFM image of VA2 confirms the presence of magnetite nanoparticles with single magnetic domains of the size 40nm. MFM was carried out with the help of Srikanth Raghavan (WVU). 


\section{Chapter4}

\section{Conclusions and Future Directions}

The proposed mechanism in this study states that the Mms6 is a magnetosome membraneassociated protein and the hydrophilic C-terminal domain, which contains acidic acids, forms a negatively charged surface. The carboxyl groups together with hydroxyl groups may serve as the template for iron binding and the formation of magnetite particles with defined size and morphology.

The investigation of sizes and morphologies of magnetite nanoparticles synthesized in the presence of VAMms6, VA2 and VA3 suggested that carboxyl groups and hydroxyl groups control the size and morphology. Discrete particles were seen using VA2, attributing to the high charge of carboxyl groups. The charge density of VA2 is much higher than VA-Mms6 or VA3. Formation of magnetite nanoparticles was supported by XPS results and the MFM image of nanoparticles formed in the presence of VA2, further supports the magnetic behavior of the synthesized particles. MFM images of nanoparticles synthesized in the presence of VA2 shows that nanoparticles are of size range 40nm. Dynamic light scattering results of particles synthesized in the presence of VA-Mms6, VA2 and VA3 showed a maximum size distribution at peak diameters of $88 \mathrm{~nm}, 62 \mathrm{~nm}$ and $41 \mathrm{~nm}$ respectively. Owing to the size of nanoparticles from MFM and DLS, a conclusion can be drawn that they form stable single magnetic domains. The attempt to make magnetite particles by changing the functional groups in Mms6 into carboxyl (VA2) was successful. Discrete particles were not visualized using VA-Mms6 and VA3.

Finally, based on the above observations and the experimental results, it is proposed that carboxyl group's peptides have a better control over the size and morphology of magnetite nanoparticles. The negatively charged surface of VA2 serves as a template for the formation of magnetite particles with uniform structure and morphology. 
There are several questions that need to be addressed in the near future. First, all the data regarding the sizes and morphologies of nanoparticles were just qualitative, further quantitative magnetic property measurements of the synthesized magnetite nanoparticles are required. Second, the synthesized magnetic particles always tend to aggregate and this behavior can be understood by studying the structure of Mms6, VA2 and VA3. The structural study will give a better idea of the structure relationship of Mms6, VA2, and VA3 to the formation of magnetite nanoparticles. And finally, the measurements of iron binding activities of VA2 should be carried out as it would help in producing quantitative data regarding the binding constant of iron to VA2.

An attempt was made in this study in synthesizing magnetite particles in presence of peptides coupled with biocompatible polymer PEG. Further studies should be carried out in characterizing the particles that are synthesized using PEG. The potential challenge in future would be film coating synthesized magnetite nanoparticles with a biocompatible and non-toxic polymer like PEG, dextran or chitosan. Magnetite particles are used as a contrast agent in MRI for better resolution of human internal structures. Usage of magnetite particles reduces noise signals of absorbing tissues. Hence the functionalized magnetite particles can be effectively used in medical applications like MRI. 


\section{References}

1. Kiick, K. L., Biosynthetic Methods for the Production of Advanced Protein-Based Materials. Polymer Reviews 2007, 47 (1), 1-7.

2. Robin S.Farmer, M. B. C. a. K. L. K., Biosynthesis of Protein-Based Polymeric Materials.

3. Hardy, J. G.; Scheibel, T. R., Production and processing of spider silk proteins. Journal of Polymer Science Part A: Polymer Chemistry 2009, 47 (16), 3957-3963.

4. Meyer, D. E.; Kong, G. A.; Dewhirst, M. W.; Zalutsky, M. R.; Chilkoti, A., Targeting a Genetically Engineered Elastin-like Polypeptide to Solid Tumors by Local Hyperthermia. Cancer Res 2001, 61 (4), 1548-1554.

5. Arakaki, A.; Webb, J.; Matsunaga, T., A Novel Protein Tightly Bound to Bacterial Magnetic Particles in Magnetospirillum magneticum Strain AMB-1. J. Biol. Chem. 2003, 278 (10), 8745-8750.

6. Sugimoto T, M. E., Journal of Colloid and Interface Science 1980, 74 (227).

7. J.P, J., Metal Oxide Chemistry and Synthesis:From solutions to solid state. Chichester,UK, 2000.

8. Teja, A. S.; Koh, P.-Y., Synthesis, properties, and applications of magnetic iron oxide nanoparticles. Progress in Crystal Growth and Characterization of Materials 2009, 55 (1-2), 22-45.

9. An-Hui Lu, E. L. S., and Ferdi Schuth, Angewandte Chemie International Edition 2007, 46, 1222-1244.

10. N.R.Jana, Y. C., X.Peng, Chemistry of materials 2004, 16, 3931.

11. J.Park, K. A., Y.Hwang,J.G. Park,H.J. Noh,J.Y. Kim,J.H. Park,N.M.Hwang Nature Materials 2004, 3, 891.

12. D.Langevin, Annual Review of Physical Chemistry 1992, 43 (341).

13. Carpenter, E. E., Journal of Magnetism and Magnetic Materials 2001, 225 (17).

14. Lowenstam, H. A., S.Weiner, Biomineralization. Oxford University Press: New York, 1989.

15. Levi-Kalisman, Y. R., S.Weiner,S.Addadi ,et al., structural differnces between biogenic amorphous calcium carbonate phases using absorption spectroscop. Advanced Functional Materials 2002, 12, 43-48. 
16. Diebel, C. E.; Proksch, R.; Green, C. R.; Neilson, P.; Walker, M. M., Magnetite defines a vertebrate magnetoreceptor. Nature 2000, 406 (6793), 299-302.

17. Bertani, L. E.; Weko, J.; Phillips, K. V.; Gray, R. F.; Kirschvink, J. L., Physical and genetic characterization of the genome of Magnetospirillum magnetotacticum, strain MS-1. Gene 2001, 264 (2), 257-263.

18. Joseph L. Kirschvink, A. K.-K., Barbara J.Woodford, Magnetite biomineralization in the human brain. Biophysics 1992, 89, 7683-7687.

19. Blakemore, R. P., Magnetotactic Bacteria. Science 1975, 190, 377-379.

20. Frankel, R. B.; Blakemore, R. P., Navigational compass in magnetic bacteria. Journal of Magnetism and Magnetic Materials 15-18 (Part 3), 1562-1564.

21. Magnetotactic bacteria at the geomagnetic equator : Frankel, R.B., R.P. Blakemore, F.F. Torres de Araujo, D.M.S. Esquivel and J. Danon, 1981 Science, 212(4500): 1269-1270. Deep Sea Research Part B. Oceanographic Literature Review 1981, 28 (12), 887-887.

22. Blakemore, R. P., Magnetotactic Bacteria. Annual Review of Microbiology 1982, 36 (1), 217 238.

23. Blakemore, R. P.; Maratea, D.; Wolfe, R. S., Isolation and pure culture of a freshwater magnetic spirillum in chemically defined medium. J. Bacteriol. 1979, 140 (2), 720-729.

24. Frankel, R. B., Richard P. Blakemore, Magnetite in freshwater Magnetotactic Bacteria. Science 1979, 203 (4387), 1355-1356.

25. Bazylinski, D. A.; Frankel, R. B., Magnetosome formation in prokaryotes. Nat Rev Micro 2004, 2 (3), 217-230.

26. Frankel, R. B.; Bazylinski, D. A.; Schüler, D., Biomineralization of magnetic iron minerals in bacteria. Supramolecular Science 1998, 5 (3-4), 383-390.

27. Bazylinski, D. A.; Schübbe, S.; Allen I. Laskin, S. S.; Geoffrey, M. G., Controlled Biomineralization by and Applications of Magnetotactic Bacteria. In Advances in Applied Microbiology, Academic Press: 2007; Vol. Volume 62, pp 21-62.

28. Komeili, A., Molecular Mechanisms of Magnetosome Formation. Annual Review of Biochemistry 2007, 76 (1), 351-366.

29. Frankel, R. B., Georgia C. Papaefthymiou,Richard P.Blakemore,Wendy O'brien, Fe3O4 Precipitation in Magnetotactic Bacteria. Biochimica and Biophysica Acta (BBA)-Molecular cell research 1983, 763 (2), 147-159. 
30. Chikashi Nakamura, J. B., Koji Sode, Tadashi Matsunaga, An Iron-regulated Gene,magA,Encoding an iron transport Protein of Magnetospirillum sp. Strain AMB-1*. The journal of Biological Chemistry 1995, 270 (47), 28392-28396.

31. Paoletti, L. C.; Blakemore, R. P., Hydroxamate production by Aquaspirillum magnetotacticum. J. Bacteriol. 1986, 167 (1), 73-76.

32. Dirk Schuler, E. B., Dynamics of iron uptake and Fe3O4 Biomineralization during aerobic and microaerobic growth of magnetospirillum gryphiswaldense. Journal of bacteriology 1998, $180(1), 159-162$.

33. Balkwill, D. L.; Maratea, D.; Blakemore, R. P., Ultrastructure of a magnetotactic spirillum. J. Bacteriol. 1980, 141 (3), 1399-1408.

34. Gorby, Y. A.; Beveridge, T. J.; Blakemore, R. P., Characterization of the bacterial magnetosome membrane. J. Bacteriol. 1988, 170 (2), 834-841.

35. Komeili, A.; Li, Z.; Newman, D. K.; Jensen, G. J., Magnetosomes Are Cell Membrane Invaginations Organized by the Actin-Like Protein MamK. Science 2006, 311 (5758), 242245.

36. Komeili, A.; Vali, H.; Beveridge, T. J.; Newman, D. K., Magnetosome vesicles are present before magnetite formation, and MamA is required for their activation. Proceedings of the National Academy of Sciences of the United States of America 2004, 101 (11), 3839-3844.

37. Prozorov, T., Surya K. Mallapragada,Balaji Narasimhan,Lijun Wang,Pierre palo,Marit Nilsen-Hamilton,Timothy J.Wiliams,Dennis A. Bazylinski,Ruslan Prozorov and Paul C.Canfield, Protein-Mediated Synthesis of Uniform Superparamagnetic Magnetite Nanocrystals. Advanced Functional Materials 2007, 17, 951-957.

38. Prozorov, T.; Palo, P.; Wang, L.; Nilsen-Hamilton, M.; Jones, D.; Orr, D.; Mallapragada, S. K.; Narasimhan, B.; Canfield, P. C.; Prozorov, R., Cobalt Ferrite Nanocrystals: OutPerforming Magnetotactic Bacteria. ACS Nano 2007, 1 (3), 228-233.

39. Kuhara, M.; Takeyama, H.; Tanaka, T.; Matsunaga, T., Magnetic Cell Separation Using Antibody Binding with Protein A Expressed on Bacterial Magnetic Particles. Analytical Chemistry 2004, 76 (21), 6207-6213.

40. Yoza, B.; Arakaki, A.; Maruyama, K.; Takeyama, H.; Matsunaga, T., Fully automated DNA extraction from blood using magnetic particles modified with a hyperbranched polyamidoamine dendrimer. Journal of Bioscience and Bioengineering 2003, 95 (1), 21-26. 
41. Ito, A.; Shinkai, M.; Honda, H.; Kobayashi, T., Medical application of functionalized magnetic nanoparticles. Journal of Bioscience and Bioengineering 2005, 100 (1), 1-11.

42. R.M.Cranenburgh, An equation for calculating the volumetric ratios required in a ligation reaction. Applied Genetics and Molecular Boitechnology 2004, (65), 200-202.

43. Missana, T.; Maffiotte, C.; García-Gutiérrez, M., Surface reactions kinetics between nanocrystalline magnetite and uranyl. Journal of Colloid and Interface Science 2003, 261 (1), 154-160. 


\section{Appendix A: Amino Acid Analysis}

\section{Mms6}

\begin{tabular}{|c|c|c|c|c|c|}
\hline Residue & $\begin{array}{c}\text { Conc. } \\
\text { nmol/inj }\end{array}$ & $\begin{array}{c}\text { Mole } \\
\%\end{array}$ & $\begin{array}{l}\text { Expected } \\
\text { Mole \% }\end{array}$ & $\begin{array}{l}\text { Abs. } \\
\text { Dev. }\end{array}$ & $\begin{array}{c}\text { Expected \# of } \\
\text { Residues }\end{array}$ \\
\hline cm-cys & 0.065 & 0.30 & & $0.30 \%$ & \\
\hline Asx & 3.952 & 18.41 & 20.59 & $-2.18 \%$ & 14 \\
\hline Thr & 0.244 & 1.14 & & $1.14 \%$ & \\
\hline Ser & 0.897 & 4.18 & 4.41 & $-0.23 \%$ & 3 \\
\hline Glx & 3.620 & 16.87 & 17.65 & $-0.78 \%$ & 12 \\
\hline \multicolumn{6}{|l|}{ Pro } \\
\hline Gly & 2.577 & 12.01 & 11.76 & $0.24 \%$ & 8 \\
\hline Ala & 2.020 & 9.41 & 8.82 & $0.59 \%$ & 6 \\
\hline \multicolumn{6}{|l|}{ Cys } \\
\hline Val & 1.480 & 6.90 & 5.88 & $1.01 \%$ & 4 \\
\hline Met & 0.178 & 0.83 & 2.94 & $-2.11 \%$ & 2 \\
\hline Ile & 0.670 & 3.12 & 2.94 & $0.18 \%$ & 2 \\
\hline Leu & 0.949 & 4.42 & 2.94 & $1.48 \%$ & 2 \\
\hline Tyr & 0.153 & 0.71 & & $0.71 \%$ & \\
\hline Phe & 0.193 & 0.90 & & $0.90 \%$ & \\
\hline His & 2.449 & 11.41 & 13.24 & $-1.82 \%$ & 9 \\
\hline Lys & 0.812 & 3.78 & 2.94 & $0.84 \%$ & 2 \\
\hline \multicolumn{6}{|l|}{ TRP } \\
\hline Arg & 1.204 & 5.61 & 5.88 & $-0.27 \%$ & 4 \\
\hline & $\begin{array}{c}\text { Total } \\
\text { Nmol/Inj.: }\end{array}$ & 21.46 & & & 68 \\
\hline & & 99.70 & 100.00 & & \\
\hline
\end{tabular}




\section{VA2}

\begin{tabular}{|c|c|c|c|c|c|}
\hline Residue & $\begin{array}{c}\text { Conc. } \\
\text { nmol/inj }\end{array}$ & $\begin{array}{c}\text { Mole } \\
\%\end{array}$ & $\begin{array}{c}\text { Expected } \\
\text { Mole\% }\end{array}$ & $\begin{array}{l}\text { Abs. } \\
\text { Dev. }\end{array}$ & $\begin{array}{l}\text { Expected } \\
\quad \text { \# of } \\
\text { Residues }\end{array}$ \\
\hline cm-cys & 0.065 & 0.30 & & $0.30 \%$ & \\
\hline Asx & 3.952 & 18.41 & 20.59 & $-2.18 \%$ & 14 \\
\hline Thr & 0.244 & 1.14 & & $1.14 \%$ & \\
\hline Ser & 0.897 & 4.18 & 4.41 & $-0.23 \%$ & 3 \\
\hline GIx & 3.620 & 16.87 & 17.65 & $-0.78 \%$ & 12 \\
\hline \multicolumn{6}{|l|}{ Pro } \\
\hline Gly & 2.577 & 12.01 & 11.76 & $0.24 \%$ & 8 \\
\hline Ala & 2.020 & 9.41 & 8.82 & $0.59 \%$ & 6 \\
\hline \multicolumn{6}{|l|}{ Cys } \\
\hline Val & 1.480 & 6.90 & 5.88 & $1.01 \%$ & 4 \\
\hline Met & 0.178 & 0.83 & 2.94 & $-2.11 \%$ & 2 \\
\hline Ile & 0.670 & 3.12 & 2.94 & $0.18 \%$ & 2 \\
\hline Leu & 0.949 & 4.42 & 2.94 & $1.48 \%$ & 2 \\
\hline Tyr & 0.153 & 0.71 & & $0.71 \%$ & \\
\hline Phe & 0.193 & 0.90 & & $0.90 \%$ & \\
\hline His & 2.449 & 11.41 & 13.24 & $-1.82 \%$ & 9 \\
\hline Lys & 0.812 & 3.78 & 2.94 & $0.84 \%$ & 2 \\
\hline \multicolumn{6}{|l|}{ TRP } \\
\hline Arg & 1.204 & 5.61 & 5.88 & $-0.27 \%$ & 4 \\
\hline
\end{tabular}

\begin{tabular}{|c|c|}
\hline $\begin{array}{l}\text { Total } \\
\text { Nmol/Inj.: }\end{array}$ & 21.46 \\
\hline & 99.70 \\
\hline
\end{tabular}




\section{Appendix B: XPS Spectra}

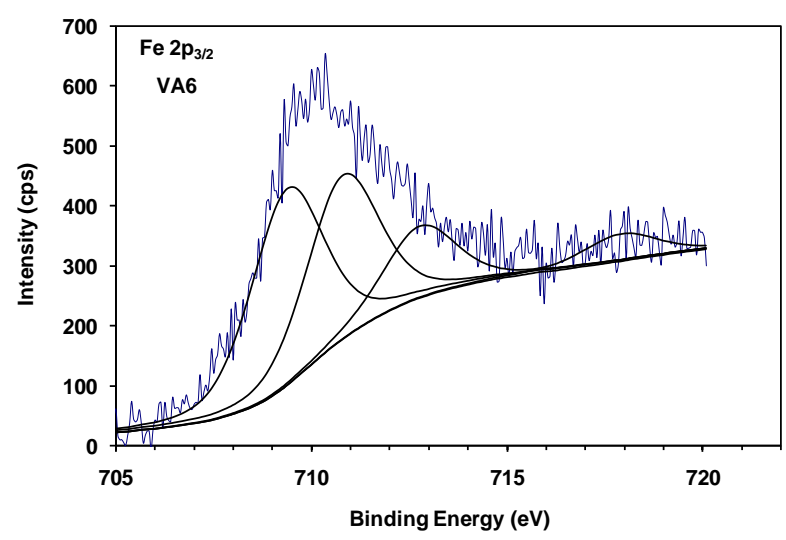

(a)

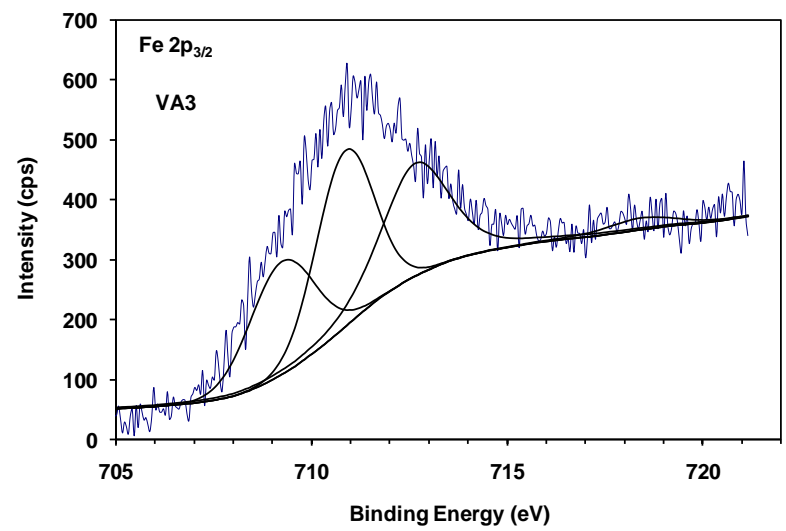

(c)

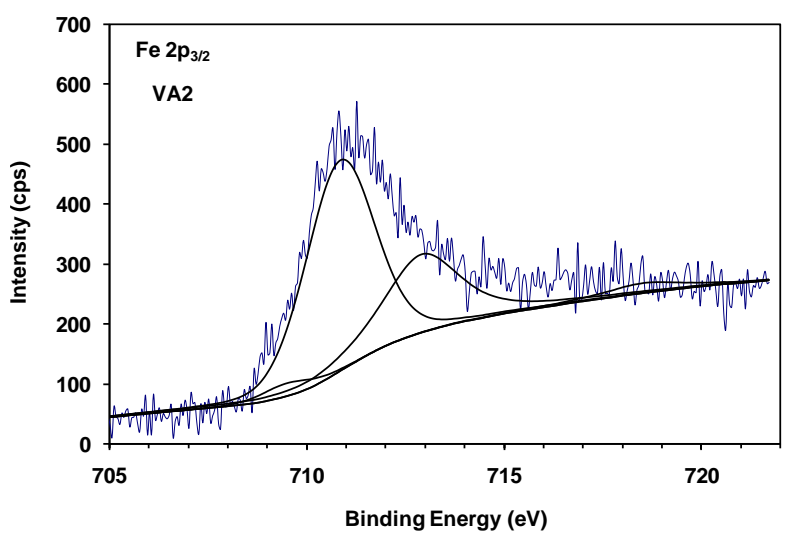

(b)

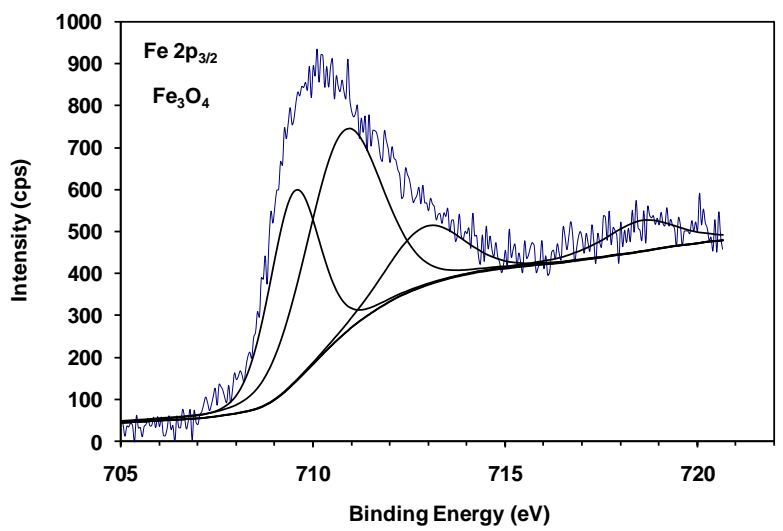

(d)

XPS spectra of magnetite particles synthesized in the presence of (a) VA-Mms6, (b) VA2, (c)VA3 and (d) standard magnetite particles 